\title{
Propranolol promotes bone formation and limits resorption through novel mechanisms during anabolic parathyroid hormone treatment in female C57BL/6J mice
}

Annika Treyball, $\mathrm{BA}^{1}$, Audrey C. Bergeron, $\mathrm{MS}^{1}$, Daniel J. Brooks, $\mathrm{MS}^{2}$, Audrie L. Langlais $\mathrm{BS}^{1,3}$, Hina Hashmi, $\mathrm{BS}^{1}$, Kenichi Nagano, DDS, $\mathrm{PhD}^{4}$, Deborah Barlow ${ }^{5}$, Kathleen T. Nevola, $\mathrm{MS}^{1,6}$, Karen L. Houseknecht, $\mathrm{PhD}^{5}$, Roland Baron, DDS, $\mathrm{PhD}^{4}$, Mary L. Bouxsein, $\mathrm{PhD}^{2,7}$, Anyonya R. Guntur, $\mathrm{PhD}^{1,3,8}$, Katherine J. Motyl, $\mathrm{PhD}^{1,3,8 *}$

${ }^{1}$ Center for Molecular Medicine, Maine Medical Center Research Institute, Scarborough, ME

${ }^{2}$ Center for Advanced Orthopaedic Studies, Beth Israel Deaconess Medical Center, Boston, MA

${ }^{3}$ Graduate School of Biomedical Sciences and Engineering, University of Maine, Orono, ME

${ }^{4}$ Department of Oral Medicine, Infection and Immunity, Harvard School of Dental Medicine, Boston, MA

${ }^{5}$ Department of Biomedical Sciences, University of New England, Biddeford, ME

${ }^{6}$ Tufts Graduate School of Biomedical Sciences, Tufts University, Boston, MA

${ }^{7}$ Department of Orthopedic Surgery, Harvard Medical School, Boston, MA

${ }^{8}$ Tufts University School of Medicine, Tufts University, Boston, MA

\section{Current Affiliations}

- Annika Treyball is presently affiliated with the Tufts University School of Medicine.

- Hina Hashmi is presently affiliated with the College of Osteopathic Medicine, University of New England.

- Kenichi Nagano is presently affiliated with the Department of Oral Pathology and Bone Metabolism, Institute of Biomedical Sciences, Nagasaki University.

*Address correspondence to:

Katherine J. Motyl

81 Research Drive

Scarborough, ME 04074

(207) 396-8004

motylk@mmc.org

\section{Conflict of Interest Statement:}

The authors have declared that no conflict of interest exists. 


\section{Abstract}

43 Although the non-selective $\beta$-blocker, propranolol, improves bone density with PTH treatment in

44 mice, the mechanism of this effect is unclear. To address this, we used a combination of in vitro

45 and in vivo approaches to address how propranolol influences bone remodeling in the context of

46 PTH treatment. In female C57BL/6J mice, intermittent PTH and propranolol had complementary

47 effects in the trabecular bone of the distal femur and L5 vertebra, with combination treatment

48 achieving micro-architectural parameters beyond that of PTH alone. Combined treatment

49 improved the serum bone formation marker, P1NP, but did not impact other histomorphometric

50 parameters relating to osteoblast function at the L5. In vitro, propranolol amplified the acute,

51 PTH-induced, intracellular calcium signal in osteoblast-like cells. The most striking finding,

52 however, was suppression of PTH-induced bone resorption. Despite this, PTH-induced receptor

53 activator of nuclear factor kappa-B ligand (RANKL) mRNA and protein levels were unaltered

54 by propranolol, which led us to hypothesize that propranolol could act directly on osteoclasts.

55 Using in situ methods, we found Adrb2 expression in osteoclasts in vivo, suggesting $\beta$-blockers

56 may directly impact osteoclasts. Taken together, this work suggests a strong anti-osteoclastic

57 effect of non-selective $\beta$-blockers in vivo, indicating that combining propranolol with PTH could

58 be beneficial to patients with extremely low bone density. 


\section{Introduction}

61 The sympathetic nervous system (SNS) plays a critical role in the regulation of bone remodeling.

62 The SNS suppresses bone formation and promotes receptor activator of nuclear factor kappa-B

63 ligand (RANKL)-mediated osteoclast recruitment, resulting in low trabecular bone volume

64 fraction in mice ${ }^{(1,2)}$. Consistent with this, tyrosine hydroxylase, one of the enzymes involved in

65 norepinephrine production, is present in nerves within bone, marrow, and periosteum ${ }^{(3)}$. The

66 major adrenergic receptor mediating the downstream effects of norepinephrine appears to be the

$67 \beta 2 \mathrm{AR}$ in mice ${ }^{(1)}$. Deletion of $\beta 2 \mathrm{AR}$, or treatment with the non-selective $\beta \mathrm{AR}$ antagonist $(\beta$ -

68 blocker) propranolol, prevents bone loss in situations of stress, antipsychotic and antidepressant

69 treatment, and in other situations in which sympathetic signaling to bone may be elevated ${ }^{(1,4-8)}$.

70 The majority of studies point toward a mechanism of $\beta 2 \mathrm{AR}$ suppressing bone formation directly

71 in the osteoblast, and activating bone resorption indirectly, through the RANKL/OPG pathway

$72^{(1,2,9)}$. Indeed, mice with an osteoblast-specific deletion of Adrb2 have a high bone density

73 phenotype as adults, with increased bone formation and reduced Rankl expression ${ }^{(10)}$. However,

74 some studies have found evidence for direct effects of $\beta 2 \mathrm{AR}$ signaling in osteoclasts ${ }^{(11,12)}$,

75 suggesting the downstream effects of elevated SNS activity may be more complex than generally

76 accepted.

77 Despite this complexity, identifying osteoporosis treatment strategies that modulate

78 sympathetic signaling remains clinically useful. $\beta$-blockers are one such group of drugs that have

79 been shown to reduce fracture risk and increase BMD in patients ${ }^{(13)(14)}$. Furthermore, rodent

80 studies have shown that combining $\beta$-blockers with teriparatide (intermittent truncated

81 parathyroid hormone, PTH) may further promote bone density. Evidence from ovariectomized

82 mice suggests that combining PTH treatment with propranolol increases bone mineral density 
83 beyond the levels achieved by PTH alone, and histomorphometric analyses indicated that

84 improvement was largely due to increased bone formation and osteoblast number ${ }^{(15)}$.

On a cellular level, evidence from in vitro and in vivo studies suggest that PTH efficacy is

86 dependent upon the presence of the $\beta 2 \mathrm{AR}$. Deletion of $A d r b 2$, the gene that encodes $\beta 2 \mathrm{AR}$,

87 prevents the anabolic effect of intermittent PTH in young and aged mice, suggesting some $\beta 2 \mathrm{AR}$

88 signaling is required ${ }^{(16)}$. One mechanism of this may be through $\beta 2 A R$ signaling allowing G-

89 protein $\beta \gamma(\mathrm{G} \beta \gamma)$ subunit to bind endosomal PTH1R, which sustains cAMP levels leading to

90 enhanced mineralization in osteoblasts ${ }^{(17)}$. cAMP signaling, however, is not the only avenue for

91 PTH effects to be transduced to the cell ${ }^{(18)(19)}$. PTH1R also signals through phospholipase $\mathrm{C}$ to

92 increase $\mathrm{Ca}^{2+}$ release from intracellular stores, as well as through arrestin-mediated mechanisms

$93{ }^{(18)(19)}$. There is an established role for intracellular $\mathrm{Ca}^{2+}$ signaling in the regulation of osteoblast

94 differentiation through the calmodulin/CamKII pathway regulating AP-1 and CREB/ATF4

95 transcription factors ${ }^{(20)}$. It has been shown that silencing of $A d r b 2$ can increase pCREB ${ }^{(21)}$, but it

96 remains unknown whether the combination of PTH treatment with $\beta 2 \mathrm{AR}$ antagonists would

97 impact these pathways.

98 To further investigate the cellular and systemic effects of co-modulation of PTH1R and

$99 \quad \beta 2 \mathrm{AR}$, we performed a series of in vitro and in vivo assays pharmacologically targeting these

100 receptors. A pharmacological approach was chosen so that any advantages of combination

101 treatments may eventually be translated to humans. Briefly, we determined that the combination

102 of PTH and propranolol in vivo increased bone volume fraction in the distal femur in part by

103 increasing markers of bone formation, which may be related to the $\beta$-blocker propranolol

104 enhancing PTH-induced $\mathrm{Ca}^{2+}$ signaling in osteoblast-like cells in vitro. More striking, however,

105 was that propranolol prevented PTH-induced bone resorption, but did not impact PTH-induced 
106 changes in RANKL or OPG pathway members. Rather, we identified that this effect may be

107 through direct anti-osteoclastogenic effects of propranolol since Adrb2 is expressed in

108 osteoclasts in vivo. In all, these findings suggest that modifications to PTH therapy that mimic

109 outcomes from propranolol treatment, or simply combining PTH with $\beta$-blockers, may be a

110 useful approach to minimizing resorption and promoting net bone accrual.

111 


\section{Results}

Propranolol improved total BMD in the presence of PTH

115 To test whether propranolol would improve PTH-induced bone formation, we treated mice with

116 either vehicle, PTH, propranolol, or PTH + propranolol from 16-20 weeks of age. Neither body

117 weight, fat mass, nor fat-free mass was altered in any of the treatment groups, suggesting that

118 any bone changes would be independent of differences in loading (Table I). As expected, PTH

119 had a significant main effect on total aBMD and aBMC, as well as on femoral aBMD (Table I).

120 Although propranolol only had a significant main effect on total aBMD, all bone parameters

121 measured by DXA were highest in the PTH + propranolol group (Table I). Interestingly, co-

122 treatment with PTH and propranolol increased total aBMD beyond that caused by PTH or

123 propranolol alone.

125 PTH and propranolol had site-specific effects on trabecular bone microarchitecture

126 To investigate the impact of PTH and propranolol treatment on bone microarchitecture, we

127 performed $\mu \mathrm{CT}$ on L5 vertebrae and femurs. Propranolol and PTH both independently improved

128 trabecular BV/TV of the L5 vertebra, but the combination of PTH and propranolol improved

$129 \mathrm{BV} / \mathrm{TV}$ and BMD above and beyond that of either treatment alone (Figure 1). This is likely due

130 to a combined effect of increased trabecular thickness and increased trabecular number, the latter

131 of which was only significantly increased by PTH when propranolol was present. Consistent

132 with this, PTH and propranolol together significantly reduced BS/BV ratio compared to

133 propranolol alone (Figure 1).

134 In the distal femur, we focused our examination of PTH and propranolol effects on two

135 distinct sites, the primary and secondary spongiosa (Figure 2). In the secondary spongiosa, PTH 
136 increased Tb. BV/TV, BMD, and Conn.D and these parameters were all increased further by

137 combined treatment with propranolol (Figure 2B-D). Although some parameters (Tb.N, Tb.Th,

$138 \mathrm{~Tb} . \mathrm{Sp}$, and BS/BV) were not altered by PTH alone, the combination reduced SMI, Tb.Sp, and

139 BS/BV, while significantly increasing Tb.N and Tb.Th (Figure 2E-I). The primary spongiosa

140 also had striking changes from PTH, including increased BV/TV, BV and BMD (Figure 2J-L),

141 but these were not exacerbated or diminished by combination PTH and propranolol treatment.

142 Tissue mineral density (TMD), a measurement of the density of the bone itself (not including any

143 marrow), was suppressed with PTH treatment, suggesting that mineral deposition may be

144 compromised (Figure 2M). Interestingly, however, propranolol significantly elevated TMD in

145 PTH-treated mice such that it was not different from vehicle-treated (Figure 2M). This indicates

146 the quality of mineralization in the primary spongiosa during combination PTH and propranolol

147 treatment may be improved compared to PTH alone.

148

149 Cortical bone microarchitecture

150 PTH significantly increased cortical area (Ct.Ar) and polar moment of inertia (pMOI) in the

151 femur midshaft, but did not significantly impact marrow area (Ma.Ar), total area (Tt.Ar), cortical

152 thickness (Ct.Th), tissue mineral density (TMD) or porosity (Figure $3 \mathrm{~A}-\mathrm{H})$. Although

153 propranolol treatment did not impact these parameters on its own, propranolol significantly

154 improved the effect of PTH on the cortical bone such that Ct.Ar, Ct.Ar/Tt.Ar, Ct.Th and TMD

155 were elevated in the PTH + propranolol group compared to propranolol alone (Figure 3A, D, E,

156 and F). The increased Ct.Ar/Tt.Ar with combination treatment is most likely due to a reduction

157 in Ma.Ar, because Tt.Ar was clearly unchanged (Figure 3B-D). 
Propranolol promoted bone formation in PTH-treated mice.

162 To determine whether co-treatment with propranolol modulated the effect of PTH on bone

163 formation, we performed serum, histomorphometric, and mRNA analyses to evaluate bone

164 remodeling activity. As expected, PTH increased the serum marker of bone formation, P1NP,

165 and this was further increased by co-treatment with PTH and propranolol (Figure 4A).

166 Histomorphometric analyses in the L5 vertebrae indicated a significant effect of PTH by 2-way

167 ANOVA on MAR and BFR parameters (Figure 4B, C). Similarly, osteoblast parameters were

168 elevated by PTH, but were not significantly modulated by the combination with propranolol.

169 Propranolol did not have a significant main effect on these parameters (except to decrease the

170 N.Ob/B.Pm) and, when combined with PTH, did not increase these indices beyond the level of

171 PTH alone (Figure 4B, C). Propranolol did, however, reduce the amount of OS/BS in PTH-

172 treated mice (Figure 4C).

173 In general, these findings contrast the serum P1NP finding, suggesting other sites may

174 have elevated bone formation with the combination treatment. Therefore, we examined mRNA

175 markers of osteoblastogenesis and osteocyte maturation in a separate site, the tibia. Although we

176 did not see significant differences in Runx2, Colla1, or Osteocalcin expression (Figure 4D-F),

177 we did observe differences in late osteoblast and osteocyte markers. First, dentin matrix acidic

178 phosphoprotein $1(\mathrm{Dmpl})$ expression was increased with PTH treatment, but there was also a

179 significant interaction $(\mathrm{p}=0.01)$ such that $\mathrm{PTH}$-induced Dmpl expression was higher in the

180 propranolol treated group, while propranolol alone had no effect in the absence of PTH (Figure

181 4G). Surprisingly, intermittent treatment with PTH induced Sost expression, in contrast to 
182 previously reported effects with chronic elevation, and Sost was elevated to a greater degree in

183 propranolol treated mice $($ Figure $4 \mathrm{H}){ }^{(22)}$. Although serum P1NP is elevated, changes in bone

184 formation (histological and mRNA-based) do not convincingly explain the improved BV/TV in

185 mice treated with PTH and propranolol.

187 as a means or consequence of promoting bone formation. Although marrow adipocyte size was

188 not influenced by PTH, there was a subtle but significant interaction effect $(\mathrm{p}<0.05)$ of PTH and

189 propranolol in both adipocyte volume / total volume (AV/TV) and adipocyte number parameters.

190 In particular, PTH tended to reduce marrow adipocyte numbers in mice not treated with

191 propranolol $(\mathrm{p}=0.08)$ but this effect was blunted in propranolol-treated mice (Figure $\mathrm{S} 1$ ).

PTH-induced intracellular calcium signaling is enhanced by propranolol

Next, we sought to test the impact of propranolol and PTH directly in osteoblasts by

195 measuring the concentration-dependence of the intracellular $\mathrm{Ca}^{2+}$ response to PTH in MC3T3-E1

196 cells differentiated for 7 days (Figure 5). PTH induced a measurable $\mathrm{Ca}^{2+}$ signal at

197 concentrations as low as $10 \mathrm{nM}$ and the peak response was observed at $1 \mu \mathrm{M}$. Using a log

198 transformation, we calculated the concentration with $50 \%$ of maximal excitation to be $66.6 \mathrm{nM}$

199 (Figure 5A), consistent with previously published reports (published $\mathrm{iCa}^{2+} \mathrm{EC}_{50}=50 \mathrm{nM}$ with

200 dynamic range $5-500 \mathrm{nM})^{(23)}$. Therefore, we used a concentration of $100 \mathrm{nM}$ in our studies, to be

201 within the dynamic range of the concentration-response curve, but also within the concentrations

202 used in previous publications demonstrating functional effects of PTH on osteoblasts ${ }^{(24)}$. Next,

203 we found that pre-treatment with propranolol significantly increased the intracellular $\mathrm{Ca}^{2+}$ signal 
204 induced by PTH (Figure 5B, C). This is in contrast to treatment with propranolol alone, which

205 did not induce any intracellular $\mathrm{Ca}^{2+}$ signal (Figure 5B).

207 whether combined PTH and propranolol treatment had any functional consequence in

208 osteoblasts, we examined gene expression of relevant receptors (Figure S2) and osteoblast

209 markers after acute treatment with PTH, propranolol or both (Figure 5D-G). Although there were

210 no differences in early osteoblastogenic markers Runx2 (Figure 5D) and Sp7 (not shown), PTH

211 induced Osteocalcin expression (main effect of PTH $p=0.016$ ) similarly in both vehicle and

212 propranolol treated cells but only the group treated with PTH alone (no propranolol present)

213 reached pairwise statistical significance (Figure 5E). Because intracellular $\mathrm{Ca}^{2+}$ has been shown

214 to modulate AP-1 family transcription factors, we examined gene expression of Fos.

215 Interestingly, the PTH-induced increase in Fos was higher when propranolol was present (Figure

$2165 \mathrm{~F}$ ), consistent with propranolol promoting PTH-induced intracellular $\mathrm{Ca}^{2+}$ levels. One

217 established mechanism of osteoanabolism from PTH is through increased expression and

218 autocrine signaling of IGF- $1^{(24)}$. We found a significant increase in Igfl expression only in the

219 PTH and propranolol co-treated group (Figure 5G). These findings suggest propranolol may

220 improve bone formation from PTH in part through increasing intracellular $\mathrm{Ca}^{2+}$ signaling and

221 promoting expression of Igfl.

222

223 PTH-induced osteoclast activity was blocked by propranolol

224 Since PTH is known to enhance resorption, we next investigated whether propranolol mitigates

225 resorption measurements in vivo. PTH increased expression of Ctsk and Trap5, as well as the

226 serum protein levels of the resorption marker CTx (Figure 6A-C). Interestingly, propranolol 
227 prevented the PTH-induced increases in Trap5 expression and serum CTx levels, suggesting

228 propranolol prevents PTH-induced resorption (Figure 6B, C). Consistent with the literature,

229 histomorphometry indicated that PTH increased the total number of osteoclasts (N.Oc/T.Ar,

230 Figure 6D). Propranolol alone did not have any impact on the number of osteoclasts or the other

231 osteoclast parameters (Figure 6D). When combined, however, the number of osteoclasts on the

232 bone surface and within the total area measured (N.Oc/B.Pm and N.Oc/T.Ar, respectively) and

233 the osteoclast surface fraction (Oc.S/BS) was lower in mice treated with PTH and propranolol

234 compared to those treated with PTH alone (Figure 6D), interaction $\mathrm{p} \leq 0.02$ ). Notably, the PTH-

235 induced increase in N.Oc/T.Ar was completely blocked by co-treatment with propranolol

$236(p<0.01$, Figure 6D). All three lines of evidence related to osteoclasts (serum, mRNA, and

237 histomorphometry) point toward a strong effect of propranolol to reduce PTH-induced bone

238 resorption.

Propranolol can centrally suppress sympathetic activity, therefore we measured

240 norepinephrine (NE) levels in serum as well. While neither PTH nor propranolol independently

241 modulated NE, the combination treatment resulted in significantly lower circulating NE

242 compared to PTH alone (Figure 6E), suggesting a systemic lowering of sympathetic activity by

243 propranolol might be responsible for the suppressed resorption. Because the current

244 understanding of the mechanism of NE signaling-induced osteoclastogenesis is through the

245 modulation of receptor activator of nuclear factor kappa-B ligand (Rankl) expression in the

246 osteoblast, we measured circulating RANKL and found that, to our surprise, propranolol had no

247 effect on PTH-induced RANKL levels (Figure 6F). Furthermore, although PTH induced Rankl

248 gene expression in cortical bone as expected, propranolol did not have any blunting effect on

249 Rankl (Figure 6G), but did lower Opg (Figure 6H), suggesting other mechanisms were 
250 responsible for the reduced osteoclast numbers and CTx levels in PTH and propranolol treated

251 mice.

252 Previous in vitro work has suggested $\beta$ ARs may play a direct role in osteoclasts ${ }^{(11,12)}$, but

253 this has not been confirmed in vivo. To test whether $\beta 2 \mathrm{AR}$ may be directly responsible for the

254 anti-osteoclastic effects of propranolol, we first tested marrow and serum concentrations of

255 propranolol achieved after dosing mice in the same manner. Propranolol concentrations achieved

256 in the serum of mice dosed in drinking water were $14.6 \mathrm{nM}$, while bone marrow concentrations

257 were $107.7 \mathrm{nM}$ (Figure 7A). Within each mouse, approximately ten times more propranolol was

258 present in marrow compared to serum, suggesting osteoclasts are likely to have significant

259 propranolol exposure. We next examined whether Adrb2 expression was present in osteoclasts in

260 vivo using in situ hybridization. First, we used probes specific to Acp5, the gene encoding

261 TRAP5, to identify multinucleated osteoclasts (Figure 7B). Next, we co-labeled with probes

262 specific to Adrb2 and found levels of Adrb2 expression in osteoclasts comparable to that of other

263 cells in the marrow (Figure 7C). Collectively, these findings suggest that lowered NE levels

264 combined with direct suppression of osteoclasts by propranolol may explain the reduced

265 resorption and improved micro-architectural parameters in mice co-treated with PTH and

266 propranolol. 


\section{Discussion}

270 Here we show that propranolol and intermittent PTH co-treatment improves bone

271 microarchitecture beyond the levels achieved by intermittent PTH treatment alone, which is

272 consistent with previous co-treatment studies ${ }^{(15)}$. We add to this, however, the novel findings

273 that propranolol enhances tissue mineral density, which may be through promoting $\mathrm{Ca}^{2+}$

274 signaling in response to PTH in osteoblasts. We are also the first to show that propranolol

275 prevents PTH-induced resorption and that this may be through direct inhibition of osteoclast

276 activity, since Adrb2 is expressed in osteoclasts in vivo. This finding in particular suggests more

277 detailed studies examining the roles of $\beta$ ARs in osteoclasts, as well as the impact of $\beta$ AR-

278 targeting drugs, are critically needed. In the absence of $\beta$-blockers, intermittent PTH treatment

279 promotes both bone formation and resorption, which could be of concern to individuals with

280 severely lowered bone density and/or high levels of resorption. Intracortical remodeling, which

281 may lead to fracture, has been associated with serum PTH levels in humans, as well as with daily

282 intermittent PTH treatment in rabbits ${ }^{(25,26)}$. Nonetheless, PTH is very effective at building new

283 bone, so bone loss that occurs from heightened resorption needs to be weighed against its

284 anabolic activity. Our findings suggest that combining PTH with propranolol, or potentially other

$285 \beta$-blockers, may be an attractive option to prevent unwanted bone loss in patients with very low

286 BMD.

The mechanism of propranolol action on bone to prevent resorption may be in part

288 through direct effects of propranolol on osteoclasts. Neither PTH-induced serum RANKL nor

$289 R a n k l$ gene expression was suppressed by propranolol, despite clear improvement in trabecular

290 microarchitecture of the distal femur and the suppressed markers of resorption (serum CTx, Acp5

291 expression, and N.Oc/T.Ar, Figure 6). The majority of publications point toward osteoblast 
expression of RANKL as being the major mediator in the effects of the sympathetic nervous

293 system on osteoclasts ${ }^{(2,10)}$. However, our findings suggest that this is not the same mechanism

294 through which propranolol blocks resorption. In studies examining the osteoblast-mediated

295 mechanism of SNS-induced bone loss, some experiments suggested no effect of Adrb2 in

296 osteoclasts. For example, Elefteriou et al. elegantly showed that the non-specific $\beta$ AR agonist

297 isoproterenol only induces osteoclast differentiation in osteoblast and bone marrow macrophage

298 (BMM) co-cultures when wildtype, but not $A d r b 2^{-/}$, osteoblasts are present ${ }^{(2)}$. Similarly, the

299 effect of isoproterenol to induce osteoclast differentiation is not dependent upon the genotype of

300 the BMMs ${ }^{(2)}$. These data, in combination with findings from models with osteoblast-specific

301 deletions of $A d r b 2$, have led to the generally accepted tenet that osteoblasts are the sole

302 mediators of the SNS effect on bone, including the mediators of osteoclast recruitment ${ }^{(10)}$.

303 There is a relative scarcity of literature examining the effects of $\beta$-adrenergic signaling

304 directly in osteoclasts. However, Rodrigues, et al. showed that propranolol prevented

305 osteoclastogenesis of RAW 264.7 cells through suppression of NFATc1 protein expression, as

306 well as later markers of differentiation: Acp5, Ctsk, and $M m p 9^{(12)}$. This suggests a role for $\beta \mathrm{AR}$

307 signaling in controlling NFATc1, which is under the control of calcium-calmodulin and

308 calcineurin signaling. Kondo, et al. demonstrated that isoproterenol enhanced osteoclastogenesis

309 in bone marrow macrophages and RAW 264.7 cells by increasing reactive oxygen species ${ }^{(11)}$.

310 Our findings appear more aligned with these reports because we see expression of Adrb2 in

311 osteoclasts in vivo and propranolol-mediated suppression of resorption downstream of

312 osteoblast-induced RANKL. Although these findings are suggestive of a role for $\beta 2 \mathrm{AR}$ in

313 osteoclasts, additional studies are needed to establish this mechanism in vivo and in vitro, and to

314 test whether human osteoclasts would have similar properties. 
Despite the paucity of literature relating to the effects of the SNS in osteoclasts directly,

316 there is extensive evidence that Adrb2 is expressed in other cells of the myeloid lineage and that

317 the SNS plays a role in their function ${ }^{(27)}$. Indeed, the SNS is important for the innate immune

318 response required for tissue repair but can be pathologically activated during certain conditions,

319 such as heart failure. $\beta$-blockers are a common therapy for heart failure and work in part by

320 reducing inflammatory cytokine levels ${ }^{(27)}$. Systemic suppression of inflammation may also be an

321 interesting, yet unexplored, avenue to investigate the mechanism of efficacy of $\beta$-blockers in

322 improving BMD, especially with regards to resorption.

323 In contrast to our findings, global knockout of $\beta 2 \mathrm{AR}$ prevents any anabolic action of

324 PTH by preventing the PTH-induced increase in mineral apposition and osteoclast number ${ }^{(16)}$.

325 Although these findings are paradoxical in some sense, they suggest that a basal level of $\beta 2$ -

326 adrenergic signaling in bone may be required for PTH action. It is also clear that pharmaceutical

327 inhibition of $\beta 2 \mathrm{AR}$ with propranolol is mechanistically distinct from the disruption of signaling

328 through genetic deletion. Propranolol can act as an inverse agonist, meaning it has effects

329 inhibitory toward cAMP signaling even when no agonist is present, reducing spontaneous $\beta 2 \mathrm{AR}$

330 receptor activity ${ }^{(28)}$. Furthermore, propranolol also binds to the lesser expressed $\beta 1 \mathrm{AR}$ and is

331 known to have non-specific effects, including acting as a weak antagonist to some serotonin

332 receptors, which could, in turn, impact bone remodeling ${ }^{(29,30)}$. We cannot exclude the possibility

333 that propranolol is having non-specific effects in our studies, however, we did measure

334 propranolol exposure in serum and marrow and found serum levels comparable to those achieved

335 in patients (Figure 7A), suggesting clinical relevance ${ }^{(31)}$. The published binding affinity of

336 propranolol at the $\beta 2 \mathrm{AR}$ is $0.5 \mathrm{nM}$, significantly less than the $107.7 \mathrm{nM}$ achieved in bone

337 marrow (Figure 7A), thus we are clearly inhibiting $\beta 2 \mathrm{AR}$ with propranolol in vivo ${ }^{(32)}$. 
338 Interestingly, the binding affinity of NE is $300 \mathrm{nM}$, while we were measuring levels in the 1-3

$339 \mathrm{nM}$ range in serum (Figure 6E). Collectively, these outcomes suggest that our observations are a

340 result of direct effects of propranolol on $\beta 2 \mathrm{AR}$ on osteoblasts and osteoclasts, either through

341 competitive inhibition of NE binding, or through inverse agonist properties (of which, $\mathrm{IC}_{50}$

342 values are in the range of the binding affinity) ${ }^{(28)}$.

343 Moriya et al. showed that Adrb2 knockdown enhances PTH-induced phosphorylation of

344 CREB, suggesting a suppressive function of $\beta 2 \mathrm{AR}$ on PTH action ${ }^{(21)}$. This is consistent with our

345 findings that PTH effects in osteoblasts are enhanced with pharmacological $\beta 2$ AR inhibition.

346 Some intracellular scaffolding proteins, such as members of the $\mathrm{Na}^{+} / \mathrm{H}^{+}$exchange regulatory

347 cofactor (NHERF) family, selectively promote coupling of the PTH1R to the G $\alpha_{\mathrm{q}}$-PLC- $\beta$

348 signaling pathway ${ }^{(19)}$. NHERF also couples $\beta 2$ AR to the cytoskeleton, and agonist binding

349 causes uncoupling from the cytoskeleton ${ }^{(33)}$. It is unknown, however, whether propranolol might

350 uncouple $\beta 2$ AR from NHERF, G proteins and/or the other signaling components, which could

351 lead to the enhanced PTH-induced $\mathrm{Ca}^{2+}$ flux (Figure 5). Nonetheless, we observed enhanced IgfI

352 expression after co-treatment in osteoblasts, which has previously been shown to work in an

353 autocrine manner to stimulate aerobic glycolysis in osteoblasts in response to PTH-treatment at 6

354 hours ${ }^{(24)}$. In our hands, the elevation of Igfl after 1 hour of propranolol treatment suggests an

355 acceleration of this timetable, which may lead to the improved PTH effect on bone formation and

356 tissue mineral density that we observed in vivo. Further studies would be required to confirm this

357 mechanism.

358 TMD in the primary spongiosa was significantly higher with PTH and propranolol co-

359 treatment compared to PTH alone (Figure 2M). A similar trend was seen with cortical TMD

360 (Figure 3F) as well as total areal BMD assessed by DXA (Table I). Serum P1NP also indicated 
361 global increases in bone formation with the combined treatment (Figure 4A), but this was not

362 observed in dynamic histomorphometric measurements of mineral apposition or bone formation

363 in the trabecular bone of the L5 vertebra (Figure 4C). However, gene expression in cortical bone

364 of the tibia suggested more mature osteoblasts/osteocytes (Figure 4G, H), indicating that

365 propranolol may have site-specific effects. Further studies investigating the mineral properties of

366 bone exposed to both PTH and propranolol would be necessary to determine if this combination

367 of treatments may improve strength in patients and animal models.

369 humans. Yang et al. reported that $\beta$-blocker use was associated with a $17 \%$ decrease in risk of

370 fractures ${ }^{(13)}$. Toulis et al. analyzed 16 studies involving over 1.5 million subjects and found that

371 the risk of fracture was significantly reduced (by 15\%) in subjects receiving $\beta$-blockers as

372 compared to control subjects, independent of sex, fracture site, or dose ${ }^{(14)}$. In contrast to what is

373 the apparent mechanism in rodent models, $\beta 1$-selective blockers were found to be more effective

374 at reducing fractures than non-selective $\beta$-blockers (i.e. propranolol). More recently, when

375 evaluating adrenergic receptor mRNA expression in human bone biopsies, Khosla et al. found

376 that ADRB1 and ADRB2, but not ADRB3, were expressed in human bone ${ }^{(34)}$. Additionally,

377 patients treated with $\beta 1$-selective blockers had better bone microarchitecture by quantitative

378 computed tomography (qCT) than non-users, had reduced CTx levels compared to placebo-

379 treated patients, and had increased BMD at the ultradistal radius, but these results were not seen

380 in propranolol (non-selective $\beta$-blockers) treated patients. Overall, this data suggests that $\beta 1$ -

381 selective blockers may be more protective against decreased BMD and increased risk of fracture

382 than non-selective $\beta$-blockers. Whether the perceived difference between rodents and humans is 
383 due to $\beta 1 \mathrm{AR}$ being understudied in rodent models or due to an actual species-specific difference

384 in the relative importance of $\beta 1 \mathrm{AR}$ vs $\beta 2 \mathrm{AR}$ in bone remains unclear.

385 Our findings reinforce the work of others suggesting that $\beta$-blockers, which are routinely

386 used clinically, may be an effective treatment or co-treatment for osteoporosis. Importantly, here

387 we showed that propranolol prevented resorption without modulating PTH-induced RANKL,

388 suggesting that the current understanding of the mechanism of $\beta$-blocker and sympathetic

389 nervous system action on bone is incomplete. We have clear evidence of Adrb2 expression in

390 osteoclasts in vivo, and future work should further investigate the extent to which osteoclasts

391 specifically mediate the impact of the SNS on bone. Investigating these mechanisms will be

392 necessary for the accurate interpretation of clinical and preclinical studies examining how the

393 sympathetic nervous system modulates bone homeostasis and contributes to bone pathologies.

395 Methods

396 Study Approval

397 The Institutional Animal Care and Use Committee of the Maine Medical Center Research

398 Institute approved all mouse protocols.

$400 \quad$ Mice and drug treatment

401 Sixteen-week-old C57BL/6J (Jackson Laboratories, Bar Harbor, ME) female, intact mice

402 underwent baseline body weight measurements and were randomly assigned to one of four

403 treatment groups. Mice were housed 3-4 per cage and provided standard laboratory chow ad

404 libitum. Female mice were chosen because of their higher propensity to have an anabolic

405 response to intermittent PTH. Mice were treated with either vehicle, PTH, propranolol or both 
PTH and propranolol. PTH (H-1660, Bachem) was aliquoted and stored in glass vials, under

407 argon gas, at $-70^{\circ} \mathrm{C}$ as a $10^{-4} \mathrm{M}$ stock in $4 \mathrm{mM} \mathrm{HCl}$ supplemented with $0.1 \%$ bovine serum

408 albumin. PTH was thawed and diluted in $0.9 \%$ saline immediately prior to injection. Vehicle and

409 PTH $(80 \mu \mathrm{g} / \mathrm{kg})$ were administered by subcutaneous injection five days per week for four weeks.

410 Propranolol hydrochloride oral solution (West-Ward Pharmaceuticals) was dissolved in drinking

411 water at a concentration of $0.5 \mathrm{mg} / \mathrm{mL}$ and was delivered daily for four weeks to animals in the

412 propranolol and PTH + propranolol groups as described ${ }^{(4)}$. At 20 weeks-of-age, mice were

413 sacrificed one hour after treatment and tissues were either fixed in $10 \%$ buffered formalin or

414 snap-frozen in liquid nitrogen and stored at $-70^{\circ} \mathrm{C}$. A similar study was conducted with just 5

415 days of treatment to obtain additional samples for some mRNA and serum analyses and are

416 identified in the figure legends.

417 For the detection of propranolol levels in the plasma and bone marrow, sixteen-week-old

418 B6 female mice were administered propranolol dissolved in drinking water as described above.

419 Six mice were separated into three individual cages (two mice/cage). Mice were treated for four

420 days, and sacrificed in the morning, one hour after exchanging treated water for untreated water.

421 Serum was isolated from whole blood and bone marrow was collected from the tibia via

422 centrifugation. Samples were kept frozen until analysis was performed; propranolol levels were

423 detected using LC/MS-MS (see methods below).

425 Dual-energy X-ray absorptiometry (DXA)

426 Mice underwent DXA measurements at baseline and at 20 weeks of age for fat-free mass, fat

427 mass, bone mineral density, and bone mineral content using the PIXImus dual-energy X-ray

428 densitometer (GE-Lunar, Madison, WI). The instrument was calibrated daily with a mouse 
429 phantom provided by the manufacturer. Mice were anesthetized with isoflurane and placed

430 ventral side down with each limb and tail positioned away from the body. Full body scans were

431 obtained, and X-ray energy absorptiometry data were gathered and processed with manufacturer-

432 supplied software (Lunar PIXImus 2, version 2.1). The head was specifically excluded from all

433 analyses due to concentrated mineral in skull and teeth.

Micro-computed tomography $(\mu \mathrm{CT})$

436 A high-resolution desktop micro-tomographic imaging system ( $\mu$ CT40, Scanco Medical AG,

437 Bruttisellen, Switzerland) was used to assess the microarchitecture of the fifth lumbar (L5)

438 vertebral body and the femur in accordance with published guidelines ${ }^{(35)}$. All analyses were

439 performed using the Scanco Evaluation software.

440 In the L5 vertebra, scans were acquired using a resolution of $10 \mu \mathrm{m}^{3}, 70 \mathrm{kVp}$ peak x-ray tube

441 potential, $114 \mathrm{~mA}$ x-ray tube current, $200 \mathrm{~ms}$ integration time, and were subjected to Gaussian

442 filtration and segmentation. The endocortical region of the vertebral body was manually selected

443 beginning $100 \mu \mathrm{m}$ inferior to the cranial growth plate and extending to $100 \mu \mathrm{m}$ superior to the

444 caudal growth plate. Trabecular bone was segmented from soft-tissue using a threshold of 460

$445 \mathrm{mgHA} / \mathrm{cm}^{3}$. Measurements included trabecular bone volume fraction (Tb.BV/TV, \%), trabecular

446 thickness (Tb.Th, mm), trabecular number (Tb. $\mathrm{N}, \mathrm{mm}^{-1}$ ), trabecular separation (Tb.Sp, mm),

447 connectivity density (Conn.D, $\mathrm{mm}^{-3}$ ), and trabecular bone mineral density (Tb.BMD,

$\left.448 \mathrm{mgHA} / \mathrm{cm}^{3}\right)$.

449 To address microarchitecture in the primary and secondary spongiosa of the distal femur and

450 the cortical bone of the femur midshaft, scans were acquired with the same parameters used for

451 the L5 vertebrae. The primary spongiosa region of interest started at the peak of the distal growth 
452 plate and extended proximally for $500 \mu \mathrm{m}$ (50 transverse slices) and included the whole cross-

453 section of the bone. The secondary spongiosa region of interest started immediately superior to

454 the primary spongiosa region and extended $1500 \mu \mathrm{m}$ (150 transverse slices) proximally and

455 included the endocortical region of the bone. In both regions, bone was segmented from soft-

456 tissue using a mineral density threshold of $460 \mathrm{mgHA} / \mathrm{cm}^{3}$. Trabecular bone in the endocortical

457 area of the secondary spongiosa region was analyzed for bone volume fraction (Tb.BV/TV, \%),

458 trabecular thickness (Tb.Th, mm), trabecular number (Tb.N, mm ${ }^{-1}$ ), trabecular separation (Tb.Sp,

$459 \mathrm{~mm}$ ), connectivity density (Conn.D, $\mathrm{mm}^{-3}$ ), and trabecular bone mineral density (Tb.BMD,

$\left.460 \mathrm{mgHA} / \mathrm{cm}^{3}\right)$. The bone in the primary spongiosa was analyzed for bone volume, total volume,

461 and bone mineral density.

462 Cortical bone architecture was analyzed in a $500 \mu \mathrm{m}$ long region at the femoral mid-

463 diaphysis (55\% of the total femur length inferior to the top of the femoral head). Cortical bone

464 was segmented from soft tissue using a threshold of $700 \mathrm{mgHA} / \mathrm{cm}^{3}$. Measurements included

465 cortical bone area $\left(\mathrm{Ct} . \mathrm{Ar}, \mathrm{mm}^{2}\right)$, total cortical cross-sectional area (Tt.Ar, $\left.\mathrm{mm}^{2}\right)$, cortical bone

466 area fraction (Ct.Ar/Tt.Ar, \%), cortical thickness (Ct.Th, mm) and cortical porosity (\%).

469 Tibiae were fixed in 10\% neutral-buffered formalin and transferred to $70 \%$ ethanol after 24

470 hours. Samples were decalcified, paraffin-embedded, sectioned, and stained with hematoxylin

471 and eosin. Adipocyte size and number in the marrow in the region of the secondary spongiosa

472 were analyzed with BIOQUANT OSTEO software (BIOQUANT Image Analysis Corporation,

473 Nashville, TN). Total adipocyte area was divided by total area (marrow plus trabecular bone) in 
474 the secondary spongiosa and multiplied by 100 to calculate adipocyte volume / total volume

475 (AV/TV). Adipocyte number was normalized to the total area measured.

$476 \quad$ Vertebrae were fixed in $10 \%$ neutral-buffered formalin and transferred to $70 \%$ ethanol

477 after 24 hours. The fixed lumbar vertebrae (L2-L5) were dehydrated with acetone and embedded

478 in methylmethacrylate. Undecalcified 4- $\mu$ m-thick sections were obtained by microtome and

479 stained with Von Kossa method for showing the mineralized bone. The consecutive second

480 section was left unstained for the analysis of fluorescence labeling and the third section was

481 stained with $2 \%$ Toluidine Blue (pH 3.7) for the analysis of osteoblasts, osteoid, and osteoclasts.

482 The bone histomorphometric analysis was performed in the lumbar vertebra under 200X

483 magnification in a $1.35 \mathrm{~mm}$ high $\times 1.3 \mathrm{~mm}$ wide region where was located $400 \mu \mathrm{m}$ away from

484 the upper and lower growth plate using OsteoMeasure analyzing software (Osteometrics Inc.,

485 Decatur, GA), in accordance with published guidelines ${ }^{(36)}$. The structural parameters (BV/TV,

486 Tb.Th, Tb.N, and Tb.Sp) were obtained by taking an average from two different analysis of

487 consecutive sections. The structural, dynamic and cellular parameters were calculated and

488 expressed according to the standardized nomenclature ${ }^{(36)}$.

489

Enzyme Immunoassays

491 Serum concentrations of amino-terminal propeptide of type 1 procollagen (P1NP), cross-linked

492 C-telopeptide (CTx) and TNF-related activation-induced cytokine (RANKL) were measured

493 with the Rat/Mouse P1NP enzyme immunoassay (EIA), RatLaps EIA (both from

494 Immunodiagnostic Systems, Scottsdale, AZ), and the Quantikine ELISA Mouse

495 TRANCE/RANKL/TNSFSF11 Kit (R\&D Systems, Minneapolis, MN). The intraassay variations 
were $6.3 \%, 6.9 \%$ and $4.3 \%$, and the interassay variations were $8.5 \%, 12 \%$ and $6.9 \%$ respectively.

497 All measurements were performed in duplicate.

499 Osteoblast assays

500 MC3T3-E1 (clone 4) cells were purchased from ATCC and maintained at a low passage number

501 in $\alpha$-MEM containing 1\% penicillin streptomycin (P/S) and 10\% fetal bovine serum (FBS). For

502 calcium assays, cells were plated overnight in 96-well black wall plates at a density of $5 \times 10^{4}$

503 cells/well. Cells were then differentiated for 7 days with ascorbic acid and $\beta$-glycerophosphate as

504 previously described ${ }^{(37)}$. PTH was aliquoted and stored as above, and thawed and diluted

505 immediately prior to use. Propranolol hydrochloride (P0884, Sigma-Aldrich) was dissolved in 1x

506 HBSS buffer containing $20 \mathrm{mM}$ HEPES for each experiment. Calcium assays were performed

507 with the FLIPR Calcium 6 Assay Kit (Molecular Devices) according to the manufacturer's

508 protocol. In brief, on day 7 of differentiation, cells were incubated with calcium dye for two

509 hours at $37^{\circ} \mathrm{C}$ and $5 \% \mathrm{CO}_{2}$. Then, fluorescence was measured on a FlexStation 3 Multi-Mode

510 Microplate Reader using SoftMax Pro 7 software (Molecular Devices) in kinetic mode in

511 response to additions of a range of concentrations of PTH. Change in relative fluorescence units

512 (maximum - minimum) is indicative of intracellular calcium $\left(\mathrm{iCa}^{2+}\right)$ levels. Concentration-

513 dependent change in max-min value was plotted on a logarithmic scale and fit with a 4-

514 parameter logistic curve to calculate the $\mathrm{EC}_{50}$. In some experiments, calcium dye incubation was

515 concurrent with pretreatment with propranolol. Additional 24-well plates were treated

516 simultaneously with PTH and propranolol for 1 hour, without the Calcium 6 reagents, and were

517 saved for mRNA analyses. 
520 Marrow was prepared for extraction by homogenization at a 1:1 ratio with $50 \mathrm{mM}$ potassium

521 phosphate buffer $\mathrm{pH}$ 7.4. A volume of $20 \mu \mathrm{L}$ of serum or marrow homogenate was combined

522 with $100 \mu \mathrm{L}$ of HPLC grade acetonitrile and vortex mixed for two minutes. Subsequent to

523 centrifugation at $14000 \mathrm{rpm}$ for five minutes, the supernatant was transferred to a 96-well plate

524 for liquid chromatograph tandem mass spectrometry (LC/MS-MS) analysis. A calibration curve

525 was formed in mouse plasma from $1.00-200 \mathrm{nM}$ by serial dilution and extracted via the same

526 methodology. An Agilent 1200 system consisting of a binary pump, column compartment and

527 autosampler was used for solvent delivery and sample introduction. Chromatographic separation

528 was performed on an Agilent Zorbax SB C18 2.1 x $50 \mathrm{~mm} 2.7 \mu \mathrm{m}$ column via a gradient using

$5290.1 \%$ formic acid in water (A) and $0.1 \%$ formic acid in acetonitrile (B). Gradient elution was

$53095 \%$ A ramping to 5\% A from 0.0-3.0 minutes, with re-equilibration at initial conditions from

5313.0 to 4.0 minutes. The flow rate was $0.75 \mathrm{~mL} / \mathrm{min}$, and column temperature was $30^{\circ} \mathrm{C}$.

532 Detection of propranolol was obtained using an Agilent 6460 triple quadrupole mass

533 spectrometer, monitoring the transition $260.0 \rightarrow 116.0$ with a fragmentor of $86 \mathrm{~V}$ and a collision

534 energy of $21 \mathrm{~V}$. The retention time of propranolol was 1.89 minutes.

536 RNA isolation and real-time PCR ( $q P C R)$

537 Total RNA was isolated from whole tibia and cortical shell using the standard TRIZOL (Sigma,

538 St. Louis, MO) method. Total RNA from cells was isolated using an RNeasy Mini Kit (Qiagen).

539 cDNA was synthesized using the High Capacity cDNA Reverse Transcriptase Kit (Applied

540 Biosystems, Foster City, CA) according to the manufacturer's instructions. mRNA expression

541 analysis was performed using an iQ SYBR Green Supermix or Taqman Gene Expression Assays 
542 with an iQ5 thermal cycler and detection system (Bio-Rad, Hercules, CA). Hypoxanthine

543 guanine phosphoribosyl transferase (Hprt) was used as an internal standard control gene (38) $^{(38)}$

544 Primer sequences are listed in the supplemental information (Table S1).

545

$546 \quad$ Norepinephrine extraction and measurements

547 A volume of $20 \mu \mathrm{L}$ of serum was combined with $100 \mu \mathrm{L}$ of HPLC grade acetonitrile and vortex

548 mixed for two minutes. Subsequent to centrifugation at $14000 \mathrm{rpm}$ for five minutes, the

549 supernatant was transferred to a 96-well plate for liquid chromatograph tandem mass

550 spectrometry (LC/MS-MS) analysis. A calibration curve was formed in mouse plasma from

$551 \quad 0.305-2500 \mathrm{nM}$ by serial dilution and extracted via the same methodology. An Agilent 1200

552 system consisting of a binary pump, column compartment and autosampler was used for solvent

553 delivery and sample introduction. Chromatographic separation was performed on a Phenomenex

554 Hydro RP 2.0 x $150 \mathrm{~mm} 4 \mu \mathrm{m}$ column via a gradient using $0.1 \%$ formic acid in water (A) and

$5550.1 \%$ formic acid in acetonitrile (B). Gradient elution was $98 \%$ A from $0-1$ minute, ramping to

$55650 \%$ A from 1.1 to 3.0 minutes, holding at $50 \%$ until 5.5 minutes, with re-equilibration at initial

557 conditions from 5.6 to 7.5 minutes. The flow rate was $0.30 \mathrm{~mL} / \mathrm{min}$, and column temperature was

$55830^{\circ} \mathrm{C}$. Detection of norepinephrine was obtained using an Agilent 6460 triple quadrupole mass

559 spectrometer, monitoring the transition $152.0 \rightarrow 107.0$ with a fragmentor of $94 \mathrm{~V}$ and a collision

560 energy of $18 \mathrm{~V}$. The retention time of norepinephrine was 1.37 minutes.

561

562 Detection of Adrb2 mRNA transcript in femur

563 Femurs were isolated from 1-week-old or 6-week-old B6 mice and fixed in 10\% neutral buffered

564 formalin for 24 hours, then decalcified in $0.5 \mathrm{M}$ EDTA pH 7.8 solution by rocking at $4 \square \mathrm{C}$ for 1 - 
5652 weeks. Samples were dehydrated in $70 \% \mathrm{EtOH}$, embedded in paraffin, and sectioned in $5 \mu \mathrm{M}$

566 sections using standard methods. RNA in situ hybridization was performed using the RNAscope

567 FFPE Multiplex Fluorescent Assay V2 (ACD Bio) per manufacturer's instructions. Briefly,

568 sections were deparaffinized followed by pre-treatment using hydrogen peroxide and target

569 retrieval was achieved by steaming for 15 minutes. Tissue sections were treated with protease,

570 and the RNAscope assay was performed as outlined by manufacturer's instructions using probes

571 for Acp5 and Adrb2. Images were acquired using a Leica TCS SP8 laser scanning confocal

572 microscope with a 20x air objective or $63 x$ oil objective.

573

574 Sample size estimation and statistics

575 Sample size for mouse experiments was estimated based on previous experiments in our

576 laboratory using trabecular BV/TV as a primary outcome. Secondary outcomes of interest

577 included serum and histomorphometric indices of bone remodeling. All statistics were performed

578 with Prism 7 statistical software (GraphPad Software, Inc., La Jolla, CA). Normally distributed

579 data were analyzed for statistically significant differences using either a two-sided Student's $t$ -

580 test or a two-way ANOVA followed by Holm-Sidak multiple comparison post hoc test, where

581 appropriate. Statistical significance was set at $p<0.05$. All data are expressed as the mean \pm

582 standard error of the mean (SEM). Outliers were handled as follows: first, any

583 scientific/biological reason for the outlier was investigated (i.e. sick mouse, degraded RNA, bad

584 histology section); second, if no explanation for the outlier was found we performed an outlier

585 test to determine if the datum was $>3$ standard deviations (SD) from the mean of the other

586 samples in that group. If the datum was > $3 \mathrm{SD}$ from the mean, it was excluded from further

587 analysis. Outlier handling did not significantly change the interpretation of the results. 


\section{Author Contributions}

589 AT was responsible for experimental design, data acquisition, data analysis, interpretation, and

590 drafting of the manuscript. ACB was responsible for experimental design, data acquisition, data

591 analysis, interpretation, drafting and critical review of the manuscript. DJB was responsible for

592 data acquisition, data analysis, interpretation, drafting of and critical revision of the manuscript.

593 ALL was responsible for experimental design, data acquisition, data analysis, interpretation and

594 drafting and critical review of the manuscript. HH was responsible for data acquisition, data

595 analysis, interpretation and drafting of the manuscript. KTN was responsible for data analysis,

596 drafting and critical review of the manuscript. $\mathrm{KN}$ was responsible for data acquisition, data

597 analysis, interpretation, drafting of and critical revision of the manuscript. DB was responsible

598 for experimental design, data acquisition, interpretation, drafting and critical revision of the

599 manuscript. KLH was responsible for experimental design, data interpretation, drafting and

600 critical revision of the manuscript. RB was responsible for data interpretation and critical

601 revision of the manuscript. MLB was responsible for data interpretation and critical revision of

602 the manuscript. ARG was responsible for experimental design, data interpretation and critical

603 revision of the manuscript. KJM was responsible for experimental design, data acquisition, data

604 analysis, interpretation, drafting and critical revision of the manuscript. All authors had final

605 approval of the manuscript. 


\section{Acknowledgements}

607 The authors thank Adriana Lelis Carvalho and Ryan Neilson for critical evaluation of the work.

608 This work was supported by the National Institute of Arthritis And Musculoskeletal And Skin

609 Diseases (NIAMS) and the National Institute of General Medical Sciences (NIGMS) of the

610 National Institutes of Health (NIH) under award numbers K01AR067858 and P20GM121301 to

611 KJM. This work utilized services of the Maine Medical Center Research Institute (MMCRI)

612 Molecular Phenotyping Core, which is supported by NIH/NIGMS P30GM106391, the

613 Physiology Core, which is supported by NIH/NIGMS P30GM106391 and P20GM121301, the

614 Histopathology and Histomorphometry Core, which is supported by NIH/NIGMS

615 P30GM106391, P20GM121301, and P30GM103392, and the Mouse Transgenic and In Vivo

616 Imaging Core which is supported by NIH/NIGMS P30GM103392. All cores also received

617 support from the Norther New England Clinical and Translational Research Network

618 NIH/NIGMS U54GM115516. The content is solely the responsibility of the authors and does not 619 necessarily represent the official views of the National Institutes of Health. 


\section{Figure Legends}

621

622 Figure 1. Propranolol improved the positive effects of PTH on trabecular bone in the L5

623 vertebrae. Mice were treated with vehicle (white), $80 \mu \mathrm{g} / \mathrm{kg}$ PTH (light blue), $0.5 \mathrm{mg} / \mathrm{ml}$

624 propranolol (gray), or PTH and propranolol (dark blue) for 4 weeks, from 16-20 weeks of age.

625 (A) Representative $\mu$ CT images from L5 vertebrae. (B-G) Trabecular bone volume fraction (Tb.

626 BV/TV), bone mineral density (BMD), number (Tb.N), thickness (Tb.Th), separation (Tb.Sp),

627 and bone surface/bone volume (BS/BV). Bars represent mean \pm standard error. * $p<0.05$,

$628 * * p<0.01$ by Holm-Sidak post hoc test after a significant two-way ANOVA.

629

630 Figure 2. Trabecular bone in the femur secondary spongiosa is enhanced by combination PTH

631 and propranolol treatment. Mice were treated with vehicle (white), $80 \mu \mathrm{g} / \mathrm{kg}$ PTH (light blue),

$6320.5 \mathrm{mg} / \mathrm{ml}$ propranolol (gray), or PTH and propranolol (dark blue) for 4 weeks, from 16-20

633 weeks of age. (A) Representative 2D (top) and 3D (bottom) images of trabecular micro

634 architecture in the primary and secondary spongiosa of the distal femur. (B-I) Trabecular

635 microarchitectural parameters from the secondary spongiosa. (J-K) Volumetric and densitometric

636 measurements from the primary spongiosa. Bars represent mean \pm standard error. ${ }^{*} p<0.05$,

$637 * * p<0.01, * * * p<0.001, * * * * p<0.0001$ by Holm-Sidak post hoc test after a significant two-way

638 ANOVA.

639

640 Figure 3. Propranolol improved cortical thickness and density in PTH-treated mice. Mice were

641 treated with vehicle (white), $80 \mu \mathrm{g} / \mathrm{kg}$ PTH (light blue), $0.5 \mathrm{mg} / \mathrm{ml}$ propranolol (gray), or PTH

642 and propranolol (dark blue) for 4 weeks, from 16-20 weeks of age. (A-H) Cortical bone 
643 microarchitectural parameters, cortical area (Ct.Ar), marrow area (Ma.Ar), total area (Tt.Ar)

644 cortical area fraction (Ct.Ar/Tt.Ar), cortical thickness (Ct.Th), cortical tissue mineral density

645 (Ct.TMD), cortical porosity, and polar moment of inertia (pMOI) were analyzed at the midshaft

646 of the femur. Bars represent mean \pm standard error. ${ }^{*} p<0.05$, ${ }^{*} * p<0.01$ by Holm-Sidak post hoc

647 test after a significant two-way ANOVA.

649 Figure 4. Propranolol improved bone formation markers in PTH-treated mice. Mice were treated

650 with vehicle (white), $80 \mu \mathrm{g} / \mathrm{kg}$ PTH (light blue), $0.5 \mathrm{mg} / \mathrm{ml}$ propranolol (gray), or PTH and

651 propranolol (dark blue) for 4 weeks, from 16-20 weeks of age. (A) Serum P1NP was measured

652 by ELISA. (B-C) Static and dynamic histomorphometry representative images and quantification

653 of architectural, bone formation and osteoblast parameters measured in L5 vertebrae. (D-H)

654 Gene expression of markers of bone formation and osteoblast maturity were analyzed in the tibia

655 and normalized by the non-modulated housekeeping gene, Hprt. Bars represent mean \pm standard

656 error. ${ }^{*} p<0.05,{ }^{*} p<0.01$ by Holm-Sidak post hoc test after a significant two-way ANOVA.

657

658 Figure 5. $\beta$-blocker propranolol potentiated osteoblast intracellular $\mathrm{Ca}^{2+}$ and $I g f l$ expression.

659 MC3T3-E1 cells were differentiated to day 7 in osteogenic media. (A) Fluorescence ratio

660 indicative of intracellular $\mathrm{Ca}^{2+}$ concentrations was expressed as a percentage of the maximum

661 level. (B) Representative traces of $100 \mathrm{nM}$ PTH or vehicle-induced fluorescence over time with

662 pretreatment of vehicle, or $0.1,1$ or $10 \mu \mathrm{M}$ propranolol. Note: vehicle + propranolol pretreatment

663 did not induce a significant signal, and traces are only slightly visible behind vehicle-only trace.

664 (C) Quantification of the maximum-minimum PTH-induced $\mathrm{Ca}^{2+}$ fluorescence after pretreatment

665 with vehicle or propranolol. One representative of three experiments (each performed in 
666 triplicate) is shown. ${ }^{*} p<0.05$ compared to vehicle-treated (black), ${ }^{\wedge} p<0.05$ compared to $100 \mathrm{nM}$

667 PTH-treated (pink) by Tukey's post-hoc test after significant one-way ANOVA. (D-K) Gene

668 expression of Runx2, Ocn, Fos, and Igfl in MC3T3-E1 cells at day 7 after 1 hour treatment with

669 vehicle (white), $100 \mathrm{nM}$ PTH (pink), $1 \mu \mathrm{M}$ propranolol (blue) or $100 \mathrm{nM}$ PTH $+1 \mu \mathrm{M}$

670 propranolol (purple). Genes are normalized to non-modulated housekeeping gene, Hprt. Each

671 data point represents the mean from an independent experiment, performed in triplicate.

672 Expression levels in vehicle-treated cells from each experiment were set to 1. Approximate $\mathrm{Ct}$

673 values of vehicle-treated groups are shown above each graph. Bars represent mean of the three

674 independent experiments \pm SEM. ${ }^{*} p<0.05, * * p<0.01$ by Holm-Sidak post hoc test after a

675 significant two-way ANOVA.

676

677 Figure 6. Propranolol prevented PTH-induced resorption but not RANKL induction. Mice were

678 treated for 4 weeks (A-F) with vehicle (white), $80 \mu \mathrm{g} / \mathrm{kg}$ PTH (light blue), $0.5 \mathrm{mg} / \mathrm{ml}$ propranolol

679 (gray), or PTH and propranolol (dark blue). (A-B) Gene expression of Ctsk and Trap5 was

680 analyzed in the whole tibia and normalized by the non-modulated housekeeping gene, Hprt. (C)

681 Serum CTx was measured by ELISA. (D) Histomorphometric analyses of osteoclast and

682 resorption parameters were measured in L5 vertebrae. (E) Serum norepinephrine (NE) was

683 measured by LC/MS/MS. (F) Serum Rankl was measured by ELISA. (G-H) Mice were treated

684 with PTH and/or propranolol for 5 days and cortical shell was collected 1 hour after the last PTH

685 or vehicle dose. Gene expression levels of Rankl and Opg were normalized to Hprt. Bars

686 represent mean \pm standard error. ${ }^{*} p<0.05,{ }^{*} p<0.01$, $* * * p<0.001$ by Holm-Sidak post hoc test

687 after a significant two-way ANOVA. 
689 Figure 7. Propranolol is present in marrow, where Adrb2 is expressed in osteoclasts in vivo. (A)

690 Left: Serum and marrow concentrations of propranolol after four days of treatment with 0.5

$691 \mathrm{mg} / \mathrm{mL}$ in the drinking water, measured by LC/MS/MS. $p$-value calculated with a paired

692 Student's t-test. Right: Marrow to serum ratio was calculated for each individual mouse. Bar

693 represent mean \pm SEM. N=6 mice. (B) 1-week-old mouse FFPE femurs were sectioned at $5 \mu \mathrm{m}$

694 and subjected to RNA hybridization with a probe specific to Acp5, red. Nuclei, blue. GP, growth

695 plate. TB, trabecular bone. BM, bone marrow. White arrowheads indicate multinucleated

696 osteoclasts. Imaged at 20x, shown is a maximum projection of a $3 \mu \mathrm{m} Z$-stack, with a step size of

$6971 \mu \mathrm{m}$. (C) Femurs from 5-6 week old C57BL/6J mice were decalcified and paraffin embedded.

698 Sections were hybridized with probes specific to Acp5 (red) and Adrb2 (green) to identify

699 osteoclasts expressing Adrb2. Nuclei, blue. Shown are representative of results from N=3

700 separate mice. TB, trabecular bone. BM, bone marrow. White arrowheads indicate

701 multinucleated osteoclasts with green Adrb2 puncta. Single Z-plane, imaged at 63x.

702

703 Figure S1. Effects of PTH and propranolol on proximal tibia bone marrow adiposity. Mice were

704 treated for 4 weeks with vehicle (white), $80 \mu \mathrm{g} / \mathrm{kg}$ PTH (light blue), $0.5 \mathrm{mg} / \mathrm{ml}$ propranolol

705 (gray), or PTH and propranolol (dark blue). (A) Tibias were decalcified and stained with H \& E.

706 Scale bar $=500 \mu \mathrm{m}$. (B-D) Adipocyte ghosts were measured using BIOQUANT OSTEO

707 software. (E) Fabp4 gene expression was measured in whole tibia and normalized to non-

708 modulated housekeeping gene Hprt. Bars represent mean \pm standard error. Indicated $p$-values

709 were determined by Holm-Sidak post hoc test after a significant interaction effect was found

710 using two-way ANOVA.

711 
712 Figure S2. Relevant receptor expression levels in osteoblast-like cells. MC3T3-E1 cells were

713 differentiated to day 7 in osteogenic media. Gene expression of Adrb1, Adrb2, Pth1r and Igflr in

714 MC3T3-E1 cells at day 7 after 1 hour treatment with vehicle (white), $100 \mathrm{nM}$ PTH (pink), $1 \mu \mathrm{M}$

715 propranolol (blue) or $100 \mathrm{nM} \mathrm{PTH}+1 \mu \mathrm{M}$ propranolol (purple). Genes are normalized to non-

716 modulated housekeeping gene, Hprt. Each data point represents the mean from an independent

717 experiment, performed in triplicate. Expression levels in vehicle-treated cells from each

718 experiment were set to 1. Approximate $\mathrm{Ct}$ values of vehicle-treated groups are shown above each

719 graph. Bars represent mean of the three independent experiments \pm SEM. ${ }^{*} p<0.05, * * p<0.01$ by

720 Holm-Sidak post hoc test after a significant two-way ANOVA.

721

722

723 


\section{References}

725 1. Takeda S, Elefteriou F, Levasseur R, Liu X, Zhao L, Parker KL, Armstrong D, Ducy P,

726 Karsenty G. Leptin regulates bone formation via the sympathetic nervous system. Cell

727 [Internet]. 2002;111(3):305-17. Available from:

728 http://www.ncbi.nlm.nih.gov/pubmed/12419242

729 2. Elefteriou F, Ahn JD, Takeda S, Starbuck M, Yang X, Liu X, Kondo H, Richards WG,

730 Bannon TW, Noda M, Clement K, Vaisse C, Karsenty G. Leptin regulation of bone resorption by the sympathetic nervous system and CART. Nature [Internet].

733 3. Mach DB, Rogers SD, Sabino MC, Luger NM, Schwei MJ, Pomonis JD, Keyser CP,

734 Clohisy DR, Adams DJ, O’Leary P, Mantyh PW. Origins of skeletal pain: sensory and 735 sympathetic innervation of the mouse femur. Neuroscience [Internet]. 2002;113(1):155-

736 66. Available from: http://www.ncbi.nlm.nih.gov/pubmed/12123694

737 4. Motyl KJ, DeMambro VE, Barlow D, Olshan D, Nagano K, Baron R, Rosen CJ,

738 Houseknecht KL. Propranolol attenuates risperidone-induced trabecular bone loss in

739 female mice. Endocrinology. 2015;156(7).

740 5. Motyl KJ, Bishop KA, Demambro VE, Bornstein SA, Le P, Kawai M, Lotinun S,

741 Horowitz MC, Baron R, Bouxsein ML, Rosen CJ. Altered thermogenesis and impaired

742 bone remodeling in Misty mice. J. Bone Miner. Res. 2013;28(9).

743 6. Yirmiya R, Goshen I, Bajayo A, Kreisel T, Feldman S, Tam J, Trembovler V, Csernus V,

744 Shohami E, Bab I. Depression induces bone loss through stimulation of the sympathetic

745 nervous system. Proc Natl Acad Sci U S A [Internet]. 2006;103(45):16876-81. Available

746 from: http://www.ncbi.nlm.nih.gov/pubmed/17075068 
747 7. Ortuno MJ, Robinson ST, Subramanyam P, Paone R, Huang YY, Guo XE, Colecraft HM,

748 Mann JJ, Ducy P. Serotonin-reuptake inhibitors act centrally to cause bone loss in mice by

749 counteracting a local anti-resorptive effect. Nat Med [Internet]. 2016;22(10):1170-9.

$750 \quad$ Available from: http://www.ncbi.nlm.nih.gov/pubmed/27595322

751 8. Yadav VK, Oury F, Suda N, Liu ZW, Gao XB, Confavreux C, Klemenhagen KC, Tanaka energy expenditure. Cell [Internet]. 2009;138(5):976-89. Available from: http://www.ncbi.nlm.nih.gov/pubmed/19737523

756 9. Ducy P, Amling M, Takeda S, Priemel M, Schilling AF, Beil FT, Shen J, Vinson C, central control of bone mass. Cell [Internet]. 2000;100(2):197-207. Available from: http://www.ncbi.nlm.nih.gov/pubmed/10660043

10. Kajimura D, Hinoi E, Ferron M, Kode A, Riley KJ, Zhou B, Guo XE, Karsenty G.

763 11. Kondo H, Takeuchi S, Togari A. beta-Adrenergic signaling stimulates osteoclastogenesis via reactive oxygen species. Am J Physiol Endocrinol Metab [Internet]. da-Silva VJ, Barbosa-Neto O, Lopes AH, Napimoga MH. Low dose of propranolol down- 
770 13. Yang S, Nguyen ND, Eisman JA, Nguyen T V. Association between beta-blockers and

771 fracture risk: A Bayesian meta-analysis. Bone. 2012.

772 14. Toulis KA, Hemming K, Stergianos S, Nirantharakumar K, Bilezikian JP. $\beta$-adrenergic

773 receptor antagonists and fracture risk: A meta-analysis of selectivity, gender, and site-

$774 \quad$ specific effects. Osteoporos. Int. 2014;

775 15. Pierroz DD, Bouxsein ML, Rizzoli R, Ferrari SL. Combined treatment with a beta-blocker and intermittent PTH improves bone mass and microarchitecture in ovariectomized mice. Bone [Internet]. 2006;39(2):260-7. Available from: http://linkinghub.elsevier.com/retrieve/pii/S8756328206002006\%5Cnpapers3://publicatio

16. Hanyu R, Wehbi VL, Hayata T, Moriya S, Feinstein TN, Ezura Y, Nagao M, Saita Y,

785 17. Jean-Alphonse FG, Wehbi VL, Chen J, Noda M, Taboas JM, Xiao K, Vilardaga JP. $\beta 2$ 786 adrenergic receptor control of endosomal PTH receptor signaling via G $\beta$ 3. Nat. Chem. $787 \quad$ Biol. 2017;

788 18. Gesty-Palmer D, Luttrell LM. "Biasing" the parathyroid hormone receptor: A novel

790 19. Cheloha RW, Gellman SH, Vilardaga JP, Gardella TJ. PTH receptor-1 signalling Mechanistic insights and therapeutic prospects. Nat. Rev. Endocrinol. 2015.

792 20. Zayzafoon M, Fulzele K, McDonald JM. Calmodulin and calmodulin-dependent kinase 
II $\alpha$ regulate osteoblast differentiation by controlling c-fos expression. J. Biol. Chem. 2005;

794 21. Moriya S, Hayata T, Notomi T, Aryal S, Nakamaoto T, Izu Y, Kawasaki M, Yamada T, expression in osteoblast-like MC3T3-E1 cells. J. Cell. Biochem. 2015;

797 22. Bellido T, Ali AA, Gubrij I, Plotkin LI, Fu Q, O’Brien CA, Manolagas SC, Jilka RL. Chronic elevation of parathyroid hormone in mice reduces expression of sclerostin by osteocytes: A novel mechanism for hormonal control of osteoblastogenesis. Endocrinology. 2005;

23. Reid IR, Civitelli R, Halstead LR, Avioli L V., Hruska KA. Parathyroid hormone acutely elevates intracellular calcium in osteoblastlike cells. Am. J. Physiol. - Endocrinol. Metab. 1987;

24. Esen E, Lee SY, Wice BM, Long F. PTH Promotes Bone Anabolism by Stimulating

813 27. De Angelis E, Pecoraro M, Rusciano MR, Ciccarelli M, Popolo A. Cross-talk between 
816 28. Baker JG. Agonist and Inverse Agonist Actions of -Blockers at the Human 2-

817 Adrenoceptor Provide Evidence for Agonist-Directed Signaling. Mol. Pharmacol. 2003;

818 29. Sozzani S, Agwu DE, McCall CE, O’Flaherty JT, Schmitt JD, Kent JD, McPhail LC.

819 Propranolol, a phosphatidate phosphohydrolase inhibitor, also inhibits protein kinase C. J.

820 Biol. Chem. 1992;

821 30. Tinajero JC, Fabbri A, Dufau ML. Serotonergic inhibition of rat leydig cell function by $822 \quad$ propranolol. Endocrinology. 1993;

823 31. Rigby J, Scott A, Hawksworth G, Petrie J. A comparison of the pharmacokinetics of

824 atenolol, metoprolol, oxprenolol and propranolol in elderly hypertensive and young

825 healthy subjects. Br. J. Clin. Pharmacol. 1985;

826 32. Meunier H, Labrie F. Specificity of the $\beta 2$-adrenergic receptor stimulating cyclic AMP

827 accumulation in the intermediate lobe of rat pituitary gland. Eur. J. Pharmacol. 1982;

828 33. Wheeler D, Sneddon WB, Wang B, Friedman PA, Romero G. NHERF-1 and the 829 cytoskeleton regulate the traffic and membrane dynamics of G protein-coupled receptors.

$830 \quad$ J. Biol. Chem. 2007;

831 34. Khosla S, Monroe DG, Farr JN. Sympathetic b 1 -adrenergic signaling contributes to 832 regulation of human bone metabolism Graphical abstract Find the latest version $\square$ : J. Clin. $833 \quad$ Invest. 2018;

834 35. Bouxsein M, Boyd S. Guidelines for assessment of bone microstructure in rodents using 835 micro-computed tomography. J. bone ... [Internet]. 2010;25(7):1468-86. Available from: 836 http://www.ncbi.nlm.nih.gov/pubmed/20533309\%5Cnhttp://onlinelibrary.wiley.com/doi/1 $837 \quad 0.1002 / \mathrm{jbmr} .141 /$ full

838 36. Dempster DW, Compston JE, Drezner MK, Glorieux FH, Kanis JA, Malluche H, Meunier 
PJ, Ott SM, Recker RR, Parfitt AM. Standardized Nomenclature, Symbols, and Units for

Bone Histomorphometry: A 2012 Update of the Report of the ASBMR Histomorphometry

843 37. Motyl KJ, Beauchemin M, Barlow D, Le PT, Nagano K, Treyball A, Contractor A, Baron

844 R, Rosen CJ, Houseknecht KL. A novel role for dopamine signaling in the pathogenesis of bone loss from the atypical antipsychotic drug risperidone in female mice. Bone. 2017;103:168-76.

847 38. Vengellur A, LaPres JJ. The role of hypoxia inducible factor $1 \alpha$ in cobalt chloride induced cell death in mouse embryonic fibroblasts. Toxicol. Sci. 2004; 
851 Table I. Body composition and areal bone parameters from mice treated with PTH and/or propranolol.

\begin{tabular}{|c|c|c|c|c|c|c|c|}
\hline & \multirow[b]{2}{*}{$\begin{array}{l}\text { Vehicle } \\
(\mathrm{N}=10)\end{array}$} & \multirow[b]{2}{*}{$\begin{array}{l}\text { PTH } \\
(\mathrm{N}=11)\end{array}$} & \multirow[b]{2}{*}{$\begin{array}{l}\text { Propranolol } \\
\quad(\mathrm{N}=9)\end{array}$} & \multirow[b]{2}{*}{$\begin{array}{c}\text { PTH + Propranolol } \\
(\mathrm{N}=11)\end{array}$} & \multicolumn{3}{|c|}{ 2-way ANOVA $p$-values } \\
\hline & & & & & PTH & Propranolol & Interaction \\
\hline Lean Mass (g) & $17.4 \pm 0.4$ & $17.9 \pm 0.3$ & $18.0 \pm 0.3$ & $17.9 \pm 0.3$ & $n s$ & $n s$ & $n s$ \\
\hline Fat Mass (g) & $2.6 \pm 0.1$ & $2.5 \pm 0.2$ & $2.6 \pm 0.2$ & $2.7 \pm 0.2$ & $n s$ & $n s$ & $n s$ \\
\hline Total aBMD $\left(\mathrm{g} / \mathrm{cm}^{2}\right)$ & $0.0527 \pm 0.0003$ & $0.0544 \pm 0.0004 * *$ & $0.0535 \pm 0.0004$ & $0.0559 \pm 0.0003^{\wedge} \# \#$ & $<0.01$ & $<0.01$ & $n s$ \\
\hline Total aBMC (g) & $0.438 \pm 0.006$ & $0.463 \pm 0.006$ & $0.444 \pm 0.007$ & $0.475 \pm 0.009 \#$ & $<0.01$ & $n s$ & $n s$ \\
\hline
\end{tabular}

$*_{p}<0.05, * * p<0.01$ compared to vehicle group.

${ }^{\wedge} p<0.05,{ }^{\wedge} p<0.01$ compared to PTH group.

$\# p<0.05, \# \# p<0.01$ compared to propranolol group. 
bioRxiv preprint doi: https://doi.org/10.1101/2020.01.08.898320; this version posted January 13,2021 . The copyright holder for this preprint (which was not certified by peer review) is the author/funder, who has granted bioRxiv a license to display the preprint in perpetuity. It is made available under aCC-BY-NC-ND 4.0 International license.

Figure 1

A

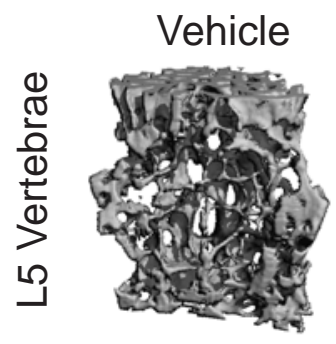

B

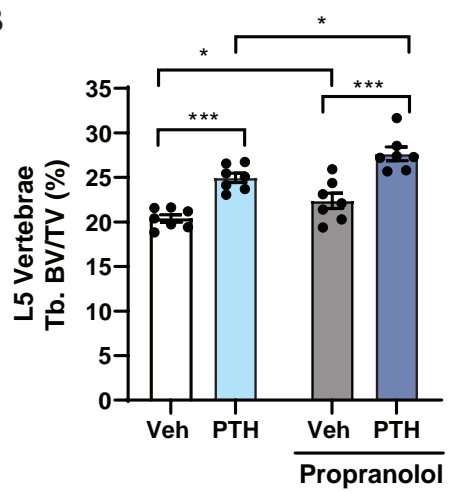

E

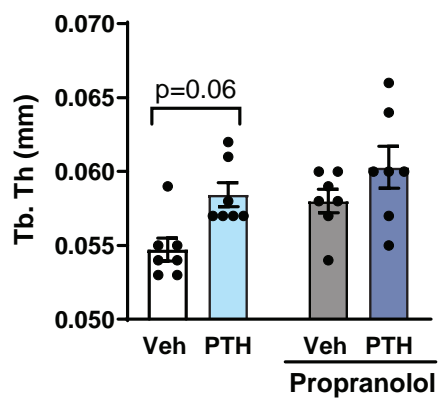

C

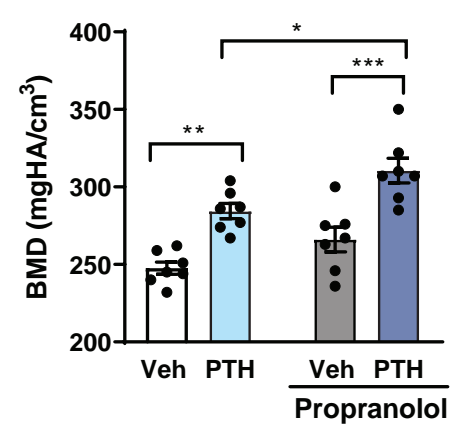

F

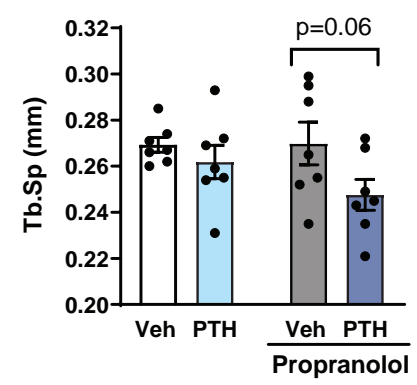

\section{Propranolol}

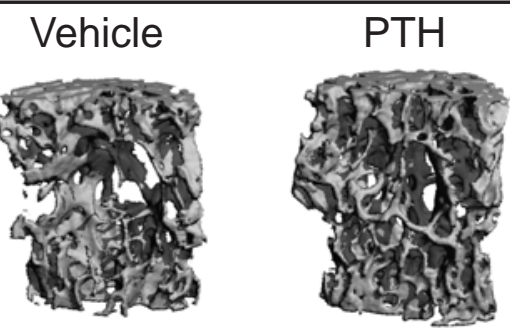

D

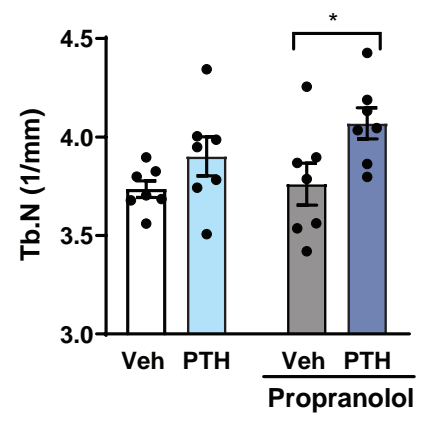

G

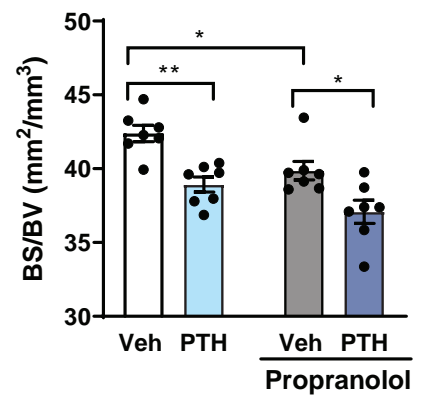


bioRxiv preprint doi: https://doi.org/10.1101/2020.01.08.898320; this version posted January 13, 2021. The copyright holder for this preprint (which was not certified by peer review) is the author/funder, who has granted bioRxiv a license to display the preprint in perpetuity. It is made available under aCC-BY-NC-ND 4.0 International license.

A Figure 2.0 International licens
Propranolol
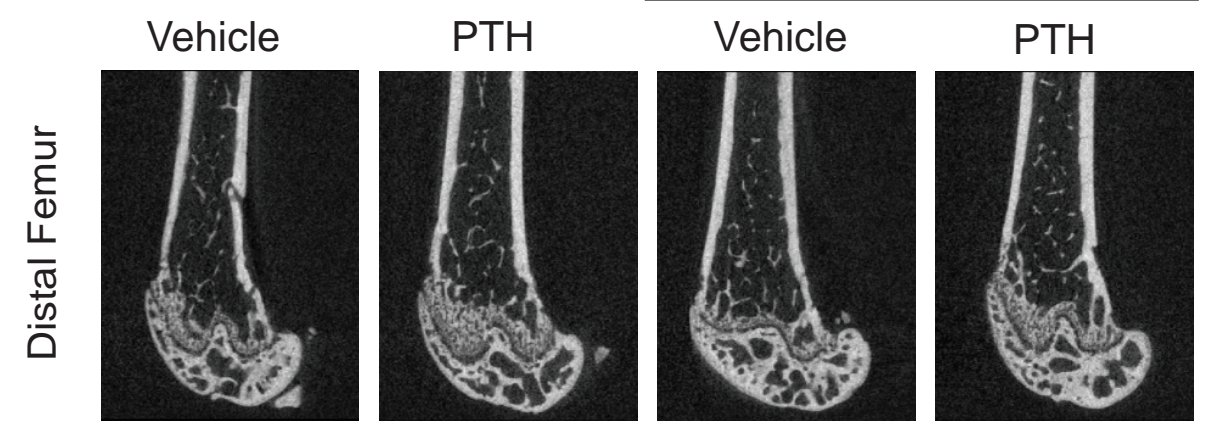

Secondary Spongiosa ] Primary Spongiosa
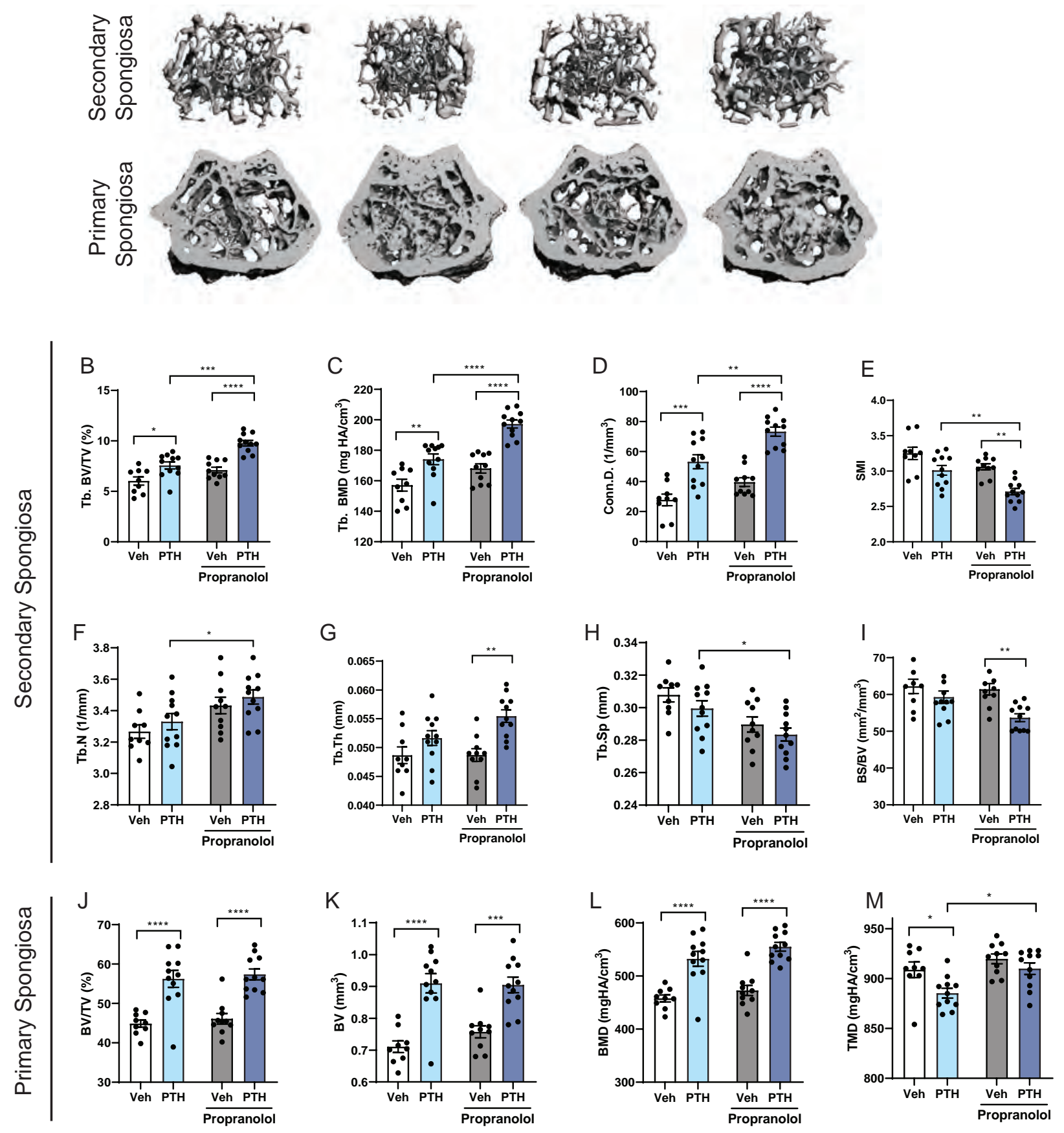
bioRxiv preprint doi: https://doi.org/10.1101/2020.01.08.898320; this version posted January 13,2021 . The copyright holder for this preprint (which was not certified by peer review) is the author/funder, who has granted bioRxiv a license to display the preprint in perpetuity. It is made available under aCC-BY-NC-ND 4.0 International license.

\section{Figure 3}

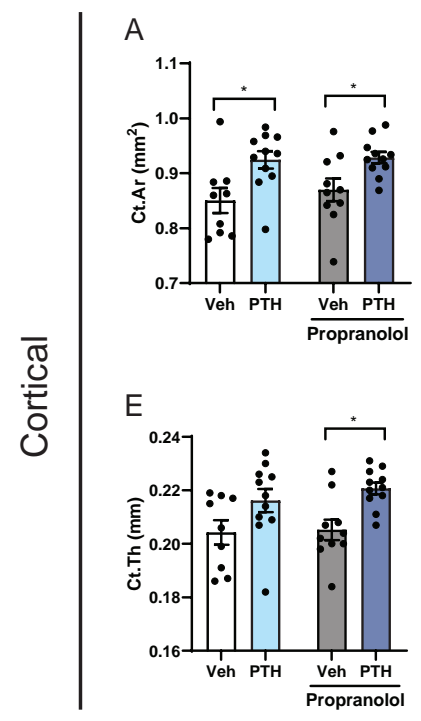

B

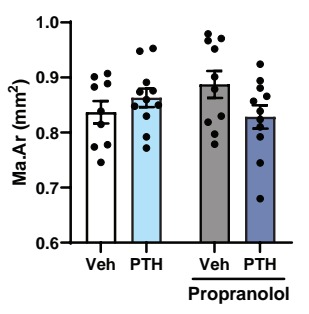

F

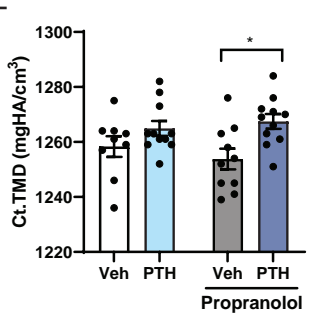

C

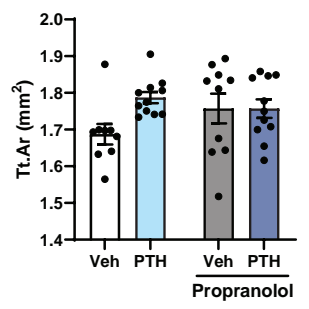

G

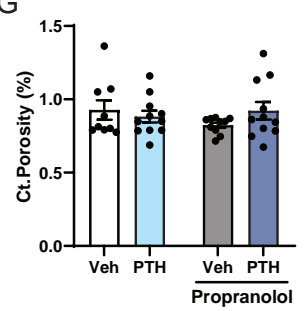

D

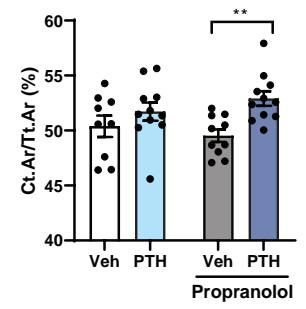

$\mathrm{H}$

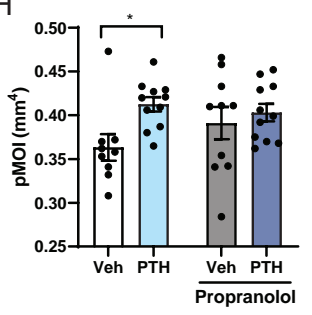


bioRxiv preprint doi: https://doi.org/10.1101/2020.01.08.898320; this version posted January 13, 2021. The copyright holder for this preprint (which was not certified by peer review) is the author/funder, who has granted bioRxiv a license to display the preprint in perpetuity. It is made available under aCC-BY-NC-ND 4.0 International license.

Figure 4

A

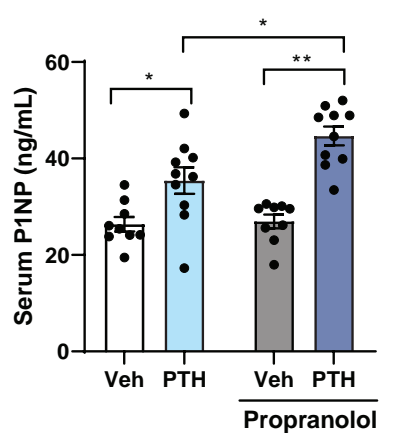

B

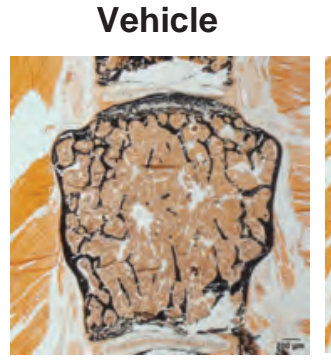

PTH

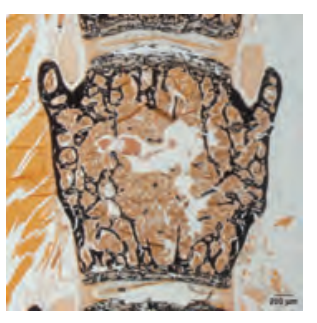

Propranolol

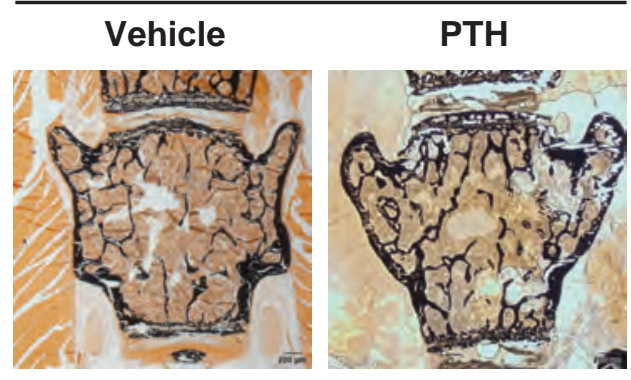

C

\begin{tabular}{|c|c|c|c|c|c|c|c|}
\hline & \multirow{2}{*}{$\begin{array}{l}\text { Vehicle } \\
(\mathrm{N}=7)\end{array}$} & \multirow{2}{*}{$\begin{array}{l}\text { PTH } \\
(\mathrm{N}=7)\end{array}$} & \multirow{2}{*}{$\begin{array}{c}\text { Propranolol } \\
(\mathrm{N}=7)\end{array}$} & \multirow{2}{*}{$\begin{array}{c}\text { PTH + Propranolol } \\
(\mathrm{N}=9)\end{array}$} & \multicolumn{3}{|c|}{ 2-way ANOVA $p$-values } \\
\hline & & & & & PTH & Propranolol & Interaction \\
\hline BV/TV (\%) & $9.4 \pm 0.8$ & $14.0 \pm 0.9^{\star \star}$ & $10.3 \pm 0.9$ & $15.6 \pm 0.4^{\# \#}$ & $<0.01$ & $n s$ & $n s$ \\
\hline Tb.Th $(\mu \mathrm{m})$ & $37.5 \pm 1.7$ & $43.5 \pm 2.1^{*}$ & $39.0 \pm 1.6$ & $45.0 \pm 1.5^{\#}$ & $<0.01$ & $n s$ & ns \\
\hline Tb.N $\left(\mathrm{mm}^{-1}\right)$ & $2.5 \pm 0.1$ & $3.2 \pm 0.1^{\star \star}$ & $2.6 \pm 0.2$ & $3.5 \pm 0.1^{\# \#}$ & $<0.01$ & ns & ns \\
\hline Tb.Sp $(\mu \mathrm{m})$ & $376 \pm 20$ & $273 \pm 14^{\star \star}$ & $349 \pm 24$ & $246 \pm 8^{\# \#}$ & $<0.01$ & ns & ns \\
\hline $\operatorname{MAR}(\mu \mathrm{m} / \text { day })^{\dagger}$ & $1.19 \pm 0.07$ & $1.65 \pm 0.07^{* *}$ & $1.12 \pm 0.13$ & $1.65 \pm 0.07^{\# \#}$ & $<0.01$ & ns & ns \\
\hline MS/BS $(\%)^{\dagger}$ & $38.3 \pm 2.1$ & $42.3 \pm 2.2$ & $39.8 \pm 3.3$ & $37.3 \pm 4.1$ & ns & ns & ns \\
\hline BFR/BV (\%/day) ${ }^{\dagger}$ & $2.58 \pm 0.21$ & $3.61 \pm 0.36$ & $2.21 \pm 0.26$ & $3.08 \pm 0.50$ & 0.01 & ns & ns \\
\hline BFR/TV $(\% / \text { day })^{\dagger}$ & $0.23 \pm 0.02$ & $0.45 \pm 0.05^{\star}$ & $0.25 \pm 0.05$ & $0.46 \pm 0.09^{\#}$ & $<0.01$ & ns & ns \\
\hline BFR/BS $\left(\mu \mathrm{m}^{3} / \mu \mathrm{m}^{2} / \mathrm{day}\right)^{\dagger}$ & $0.45 \pm 0.04$ & $0.70 \pm 0.06^{*}$ & $0.45 \pm 0.06$ & $0.62 \pm 0.08$ & $<0.01$ & ns & ns \\
\hline N.Ob/B.Pm $\left(\mathrm{mm}^{-1}\right)$ & $14.7 \pm 1.0$ & $22.5 \pm 1.5^{\star \star}$ & $12.4 \pm 0.6$ & $19.4 \pm 1.2^{\# \#}$ & $<0.01$ & 0.03 & ns \\
\hline N.Ob/T.Ar $\left(\mathrm{mm}^{-2}\right)$ & $71.1 \pm 8.5$ & $147.7 \pm 6.5^{\star \star}$ & $64.4 \pm 3.7$ & $127.0 \pm 7.9^{\# \#}$ & $<0.01$ & ns & ns \\
\hline Ob.S/B.Pm (\%) & $17.4 \pm 1.2$ & $26.8 \pm 1.8^{\star \star}$ & $14.8 \pm 0.8$ & $24.2 \pm 1.4^{\# \#}$ & $<0.01$ & $n s$ & ns \\
\hline OS/BS (\%) & $14.1 \pm 1.2$ & $18.8 \pm 2.0$ & $13.3 \pm 1.3$ & $12.5 \pm 1.2^{M}$ & $n s$ & 0.02 & ns \\
\hline O.Th $(\mu \mathrm{m})$ & $2.69 \pm 0.13$ & $3.14 \pm 0.14$ & $2.71 \pm 0.27$ & $2.76 \pm 0.12$ & ns & ns & ns \\
\hline \multicolumn{8}{|c|}{${ }^{*} p<0.05$ compared to vehicle, ${ }^{* *} p<0.01$ compared to vehicle } \\
\hline \multicolumn{8}{|c|}{$p<0.05$ compared to PTH, Mp $^{2} 0.01$ compared to PTH } \\
\hline \multicolumn{8}{|c|}{${ }^{\#} p<0.05$ compared to $\mathrm{PRO}, \# p<0.01$ compared to PRO } \\
\hline${ }^{\dagger} \mathrm{N}=4-5$ for dynamic meas & rements. & & & & & & \\
\hline
\end{tabular}

D

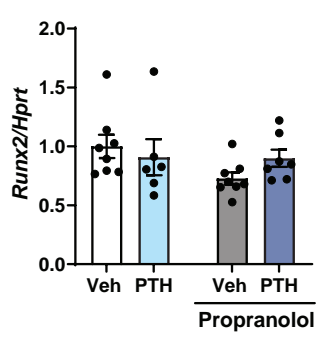

E

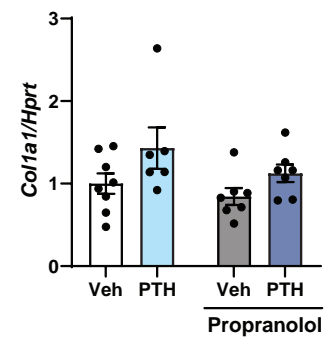

F

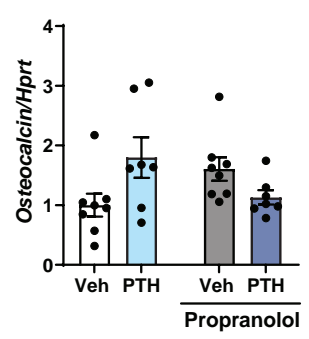

G

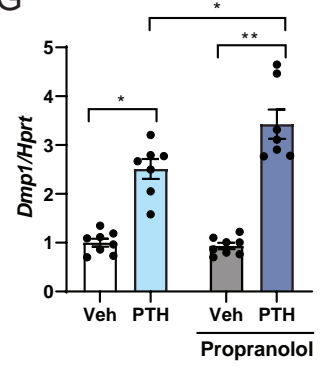

$\mathrm{H}$

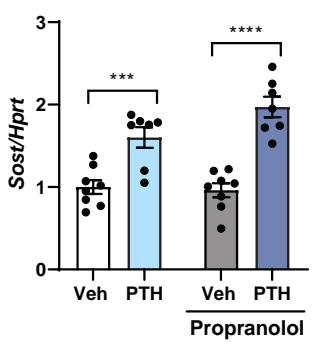


A

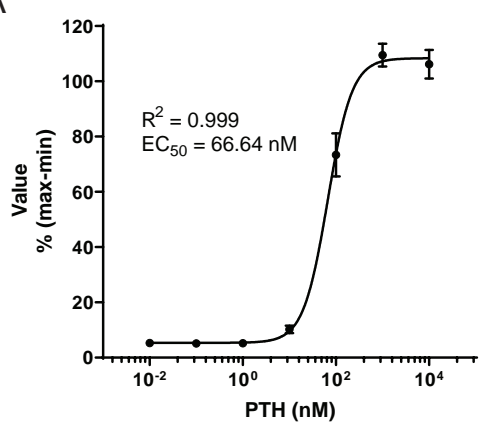

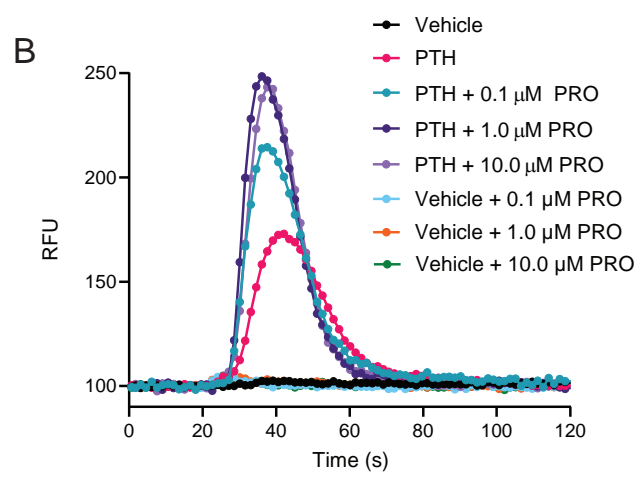

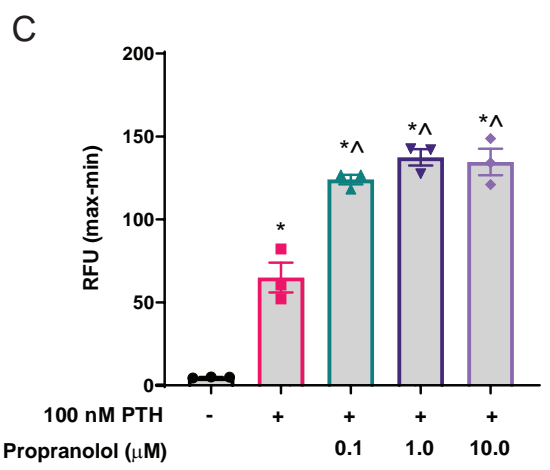

G

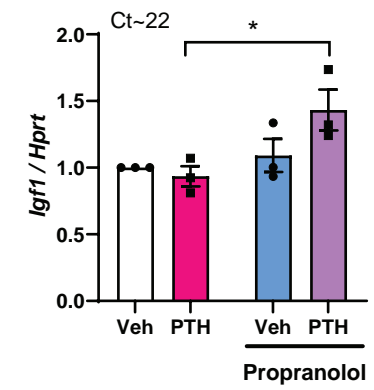

Propranolol
E

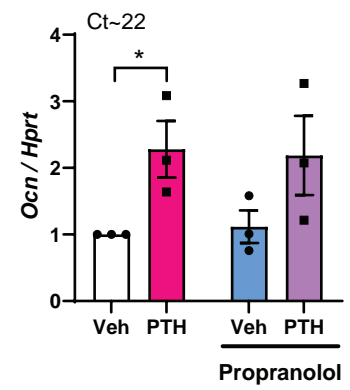

$\mathrm{F}$

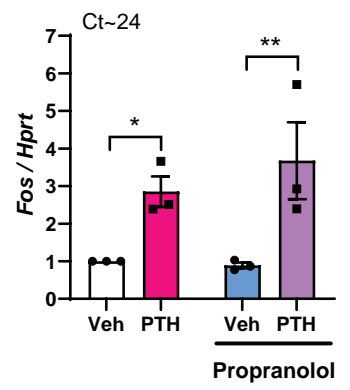

Propranolol

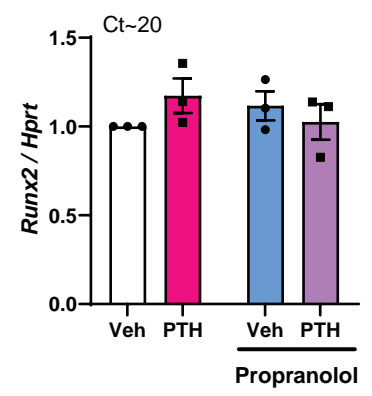


bioRxiv preprint doi: https://doi.org/10.1101/2020.01.08.898320; this version posted January 13, 2021. The copyright holder for this preprint (which was not certified by peer review) is the author/funder, who has granted bioRxiv a license to display the preprint in perpetuity. It is made available under aCC-BY-NC-ND 4.0 International license.

Figure 6

A

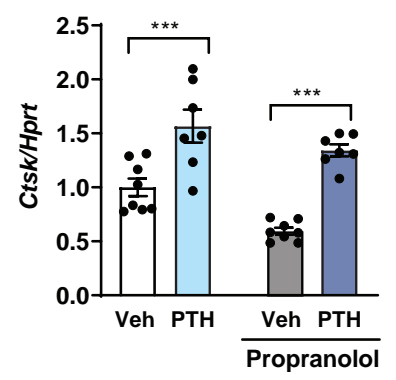

B

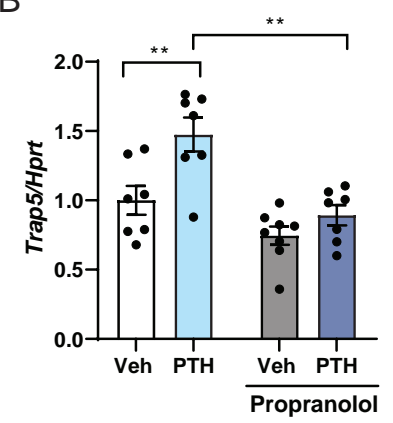

C

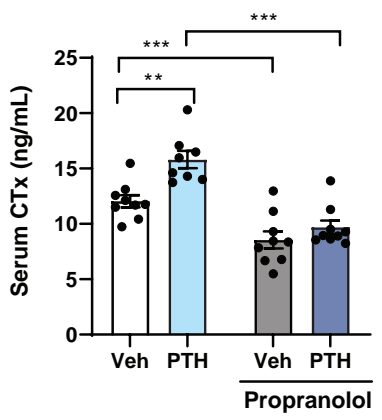

D

\begin{tabular}{|c|c|c|c|c|c|c|c|}
\hline & \multirow{2}{*}{$\begin{array}{c}\text { Vehicle } \\
(\mathrm{N}=7)\end{array}$} & \multirow{2}{*}{$\begin{array}{l}\text { PTH } \\
(\mathrm{N}=7)\end{array}$} & \multirow{2}{*}{$\begin{array}{c}\text { Propranolol } \\
(\mathrm{N}=7)\end{array}$} & \multirow{2}{*}{$\begin{array}{c}\text { PTH + Propranolol } \\
(\mathrm{N}=9)\end{array}$} & \multicolumn{3}{|c|}{ 2-way ANOVA $p$-values } \\
\hline & & & & & PTH & Propranolol & Interaction \\
\hline N.Oc/B.Pm $\left(\mathrm{mm}^{-1}\right)$ & $5.9 \pm 0.3$ & $6.2 \pm 0.2$ & $5.3 \pm 0.4$ & $4.2 \pm 0.2^{\#,}, M$ & ns & $<0.01$ & 0.02 \\
\hline N.Oc/T.Ar $\left(\mathrm{mm}^{-2}\right)$ & $28.2 \pm 2.4$ & $41.3 \pm 2.4^{\star \star}$ & $27.4 \pm 1.9$ & $27.7 \pm 1.5^{M}$ & $<0.01$ & $<0.01$ & $<0.01$ \\
\hline Oc.S/B.Pm (\%) & $14.8 \pm 0.8$ & $15.9 \pm 0.5$ & $13.1 \pm 0.9$ & $10.6 \pm 0.5^{m}$ & ns & $<0.01$ & 0.02 \\
\hline ES/BS (\%) & $5.9 \pm 0.5$ & $5.8 \pm 0.4$ & $5.0 \pm 0.7$ & $4.1 \pm 0.3^{\wedge}$ & ns & 0.01 & ns \\
\hline
\end{tabular}

${ }^{\star} p<0.05$ compared to vehicle, ${ }^{* \star} p<0.01$ compared to vehicle

$p<0.05$ compared to PTH, $n_{p}<0.01$ compared to PTH

$\# p<0.05$ compared to $P R O, \# p<0.01$ compared to PRO

E

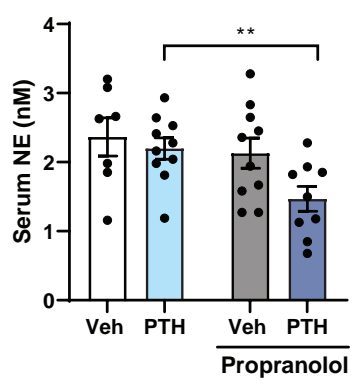

$\mathrm{F}$

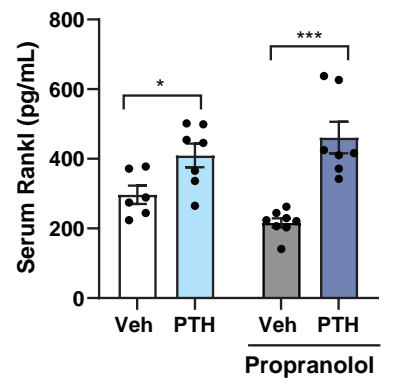

G

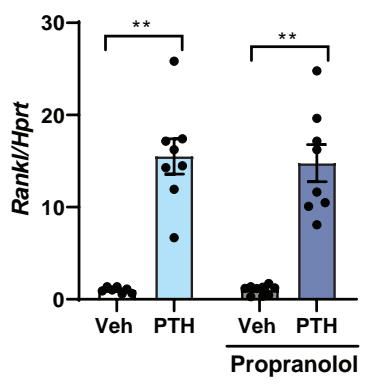

$\mathrm{H}$

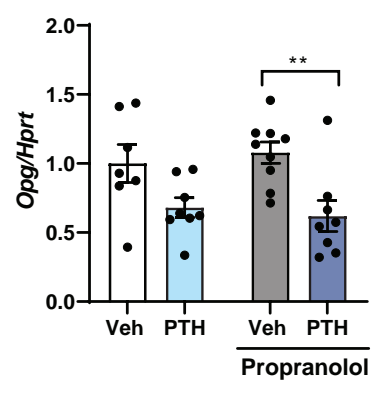


bioRxiv preprint doi: https://doi.org/10.1101/2020.01.08.898320; this version posted January 13,2021 . The copyright holder for this preprint (which was not certified by peer review) is the author/funder, who has granted bioRxiv a license to display the preprint in perpetuity. It is made available under aCC-BY-NC-ND 4.0 International license.

Figure 7

B

A

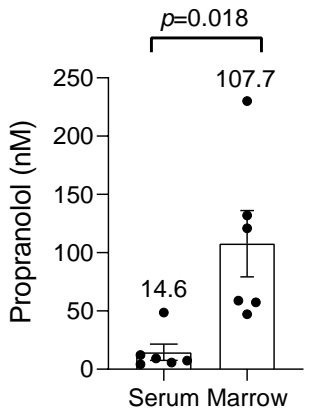

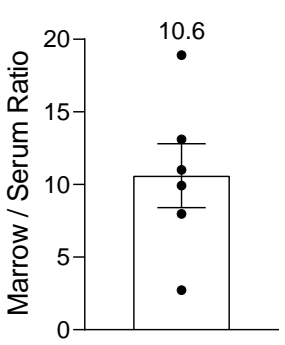

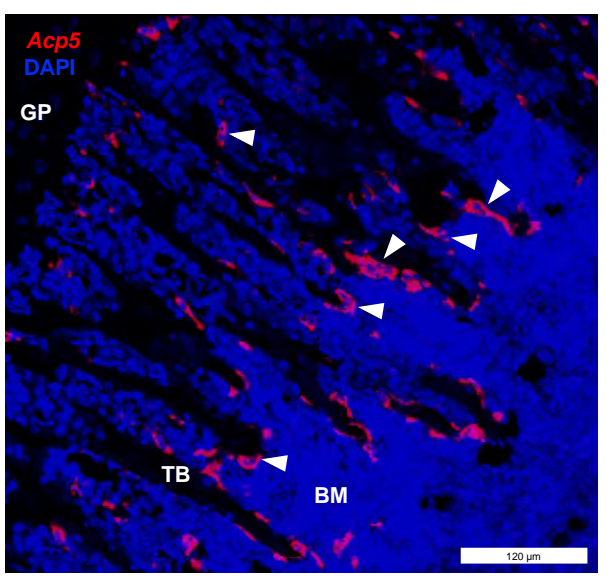

C

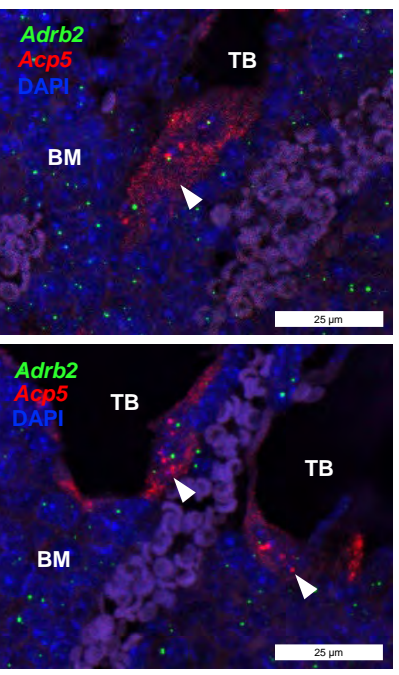


bioRxiv preprint doi: https://doi.org/10.1101/2020.01.08.898320; this version posted January 13, 2021. The copyright holder for this preprint (which was not certified by peer review) is the author/funder, who has granted bioRxiv a license to display the preprint in perpetuity. It is made available under aCC-BY-NC-ND 4.0 International license.

\section{Figure S1}

A
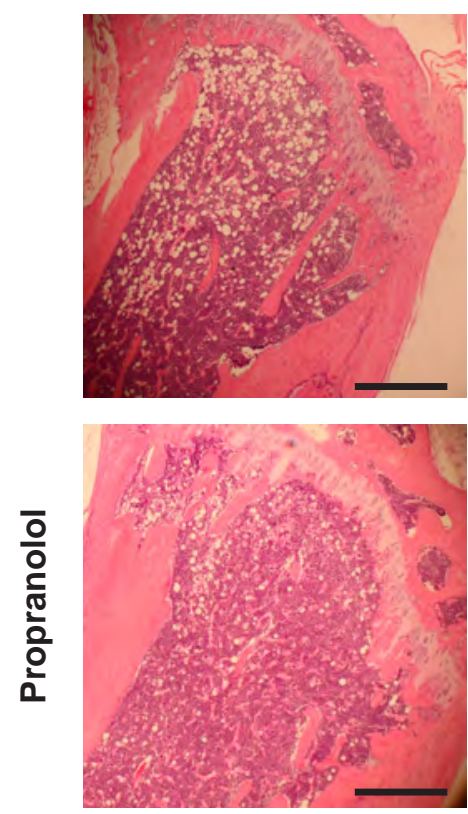

\section{PTH}
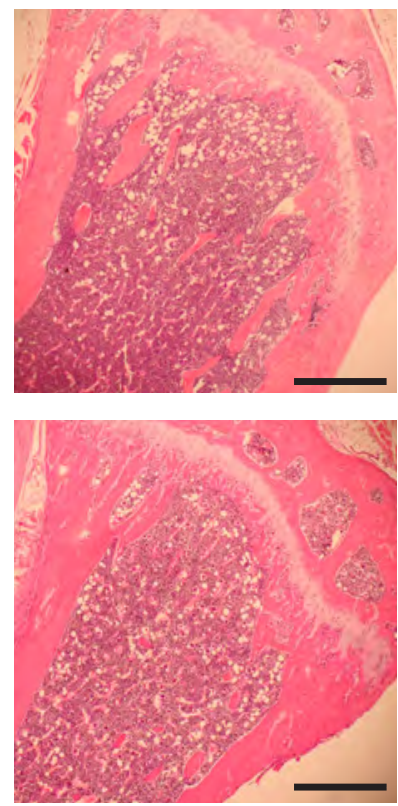

B

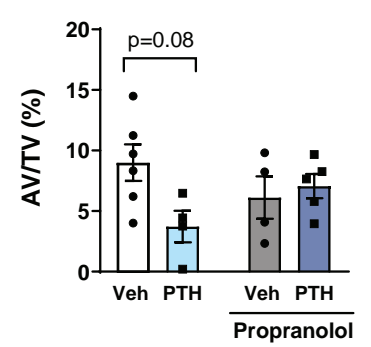

D

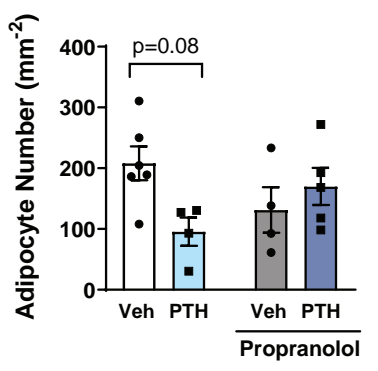

C

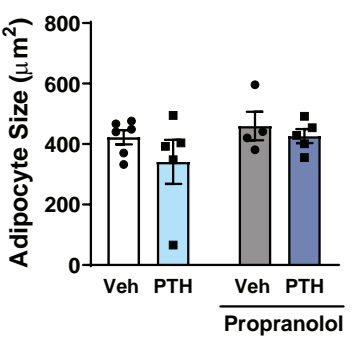

E

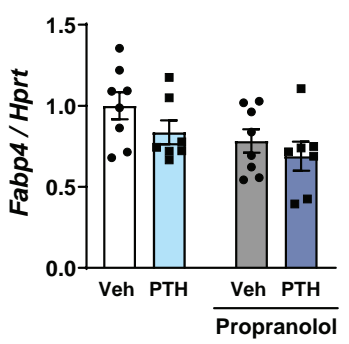


bioRxiv preprint doi: https://doi.org/10.1101/2020.01.08.898320; this version posted January 13,2021 . The copyright holder for this preprint (which was not certified by peer review) is the author/funder, who has granted bioRxiv a license to display the preprint in perpetuity. It is made available under aCC-BY-NC-ND 4.0 International license.

A

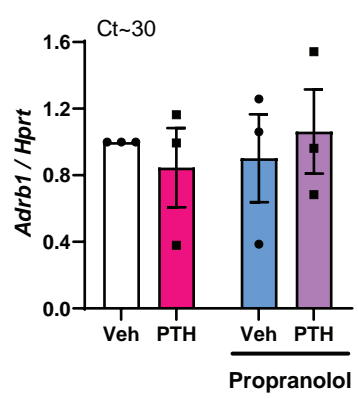

B

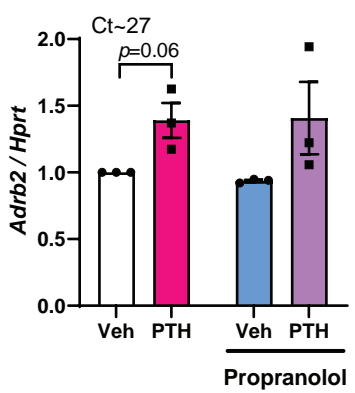

Figure S2

C

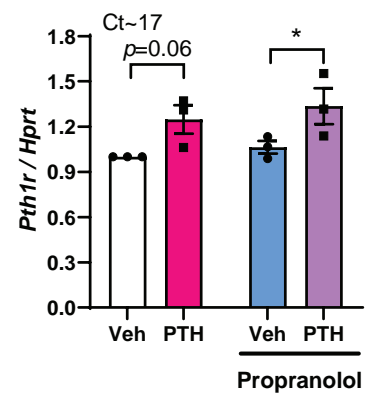

D

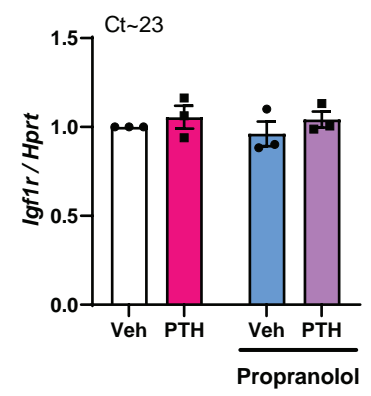

